\title{
Coumestrol Confers Partial Resistance in Soybean Plants Against Cercospora Leaf Blight
}

\author{
E. C. Silva, ${ }^{\dagger}$ P. L. Abhayawardhana, A. V. Lygin, C. L. Robertson, M. Liu, Z. Liu, and R. W. Schneider
}

First, second, fourth, and seventh authors, Department of Plant Pathology and Crop Physiology, Louisiana State University Agricultural Center, Baton Rouge 70803; third author, Department of Crop Sciences, University of Illinois, Urbana 61801; and fifth and sixth authors, Medicinal Plant Lab, School of Renewable Natural Resources, Louisiana State University Agricultural Center.

Accepted for publication 12 February 2018.

\begin{abstract}
Although previous research showed that the purple symptom of Cercospora leaf blight (CLB) is associated with lower biomass of Cercospora cf. flagellaris and lower concentrations of cercosporin, a reactive oxygen species producer, as compared with blighted leaves, the hypothesis that the purple symptom is a plant reaction to the pathogen has never been tested. In this study, we demonstrated that high levels of coumestrol (COU) were associated with purple symptoms of CLB and that COU has strong antioxidant activity. Additionally, we found that $\mathrm{COU}$ is restricted to the pigmented areas of purple leaves, and the pigmentation is restricted to the adaxial surfaces, suggesting

that COU may be acting as a sunscreen. Even though COU is associated with the purple leaf symptom, this coumestan is not the direct cause of discoloration in that COU is colorless. Quantification of chlorophyll $a$ and $b$ and total carotenoids suggested that blighted but not purple or asymptomatic leaves were undergoing photooxidative stress. Because the purple symptom is associated with high COU concentrations, lower biomass of $C$. cf. flagellaris, and lower cercosporin concentrations, we conclude that the purple symptom is a disease resistance reaction, mediated in part by COU, which provides a high level of antioxidant activity and, hence, partial resistance.
\end{abstract}

Cercospora leaf blight (CLB), as well as soybean purple seed stain (PSS), are caused by Cercospora kikuchii (Tak. Matsumoto \& Tomoy.) M. W. Gardner; however, recent findings showed that $C$. cf. flagellaris and $C$. cf. sigesbeckiae also are causal agents of these diseases in North and South America (Albu et al. 2016; Soares et al. 2015). Considered only a minor disease until 2000, CLB of soybean (Glycine max L. Merr.) causes an estimated 23\% yield loss in the United States (Wrather et al. 1997) and yield reductions of almost 2,000,000 metric tons worldwide (Wrather et al. 2010). Today, CLB is one of the most important soybean diseases in Louisiana and other states of the midsouth of the United States (Cai et al. 2009). In addition to Louisiana, CLB was reported in Nebraska and Kentucky (Geisler 2013; Hershman 2009). In South America, CLB was reported in Argentina, Brazil, and Paraguay (Almeida et al. 2005; Wrather et al. 2010).

Management of CLB and PSS with fungicides has not been satisfactory in Louisiana (Price et al. 2013). Recently, Price et al. (2015) reported resistance to methyl benzimidazole carbamate and quinone outside inhibitor fungicides in Louisiana. Additionally, the number of soybean cultivars resistant to CLB and PSS has been decreasing since 1999 (Levy et al. 2013; Moore and Wolcott 2000; Schneider et al. 2003).

C. cf. flagellaris exists as an endophyte in soybean plants during vegetative growth stages but pathogen biomass increases sharply during early reproductive growth (Chanda et al. 2014), when typical symptoms of the disease usually appear. Like many Cercospora spp., C. cf. flagellaris produces a red, nonspecific toxin called cercosporin that plays a major role in pathogenicity, symptom expression, and virulence (Fajola 1978; Kilpatrick and Johnson 1956; Ilyas et al. 1975; Upchurch et al. 1991; Velicheti and Sinclair 1994). Cercosporin is a bright red, purplish perylenequinone toxin (Daub and Chung 2007). Perylenequinone compounds such as cercosporin are

†Corresponding author: E. C. Silva; E-mail: eduardochagass@gmail.com

Funding: This work was supported by the Louisiana Soybean \& Grain Promotion Board and Brandt Consolidated.

(C) 2018 The American Phytopathological Society photoactivated, which means that light is required to activate its toxic moiety (Daub and Briggs 1983). When this toxin absorbs light, it is converted to an active triplet state. This triplet state induces the formation of reactive oxygen species (ROS), including singlet oxygen, hydrogen peroxide, and superoxide (Daub and Briggs 1983). ROS damages plant tissue and causes physiological changes in the plant cell such as peroxidation of membrane lipids, membrane breakdown, nutrient leakage, and death of cells (Daub and Briggs 1983; Daub and Chung 2007).

Walters (1980) reported that the development of symptoms of CLB begins as a leathery appearance and purple bronze color on the adaxial surface of leaves and, as the disease progresses, purple leaves become necrotic, leading to blight symptoms and defoliation in the upper canopy of soybean plants. Walters (1980) also suggested that the purple pigmentation of soybean plants affected by CLB is the result of the accumulation of cercosporin (red in color) with the green background of the leaves. However, previous studies showed that purple and blight symptoms of CLB are not necessarily correlated and may be independent of each other (Silva et al. 2015). Silva's work also showed that cercosporin concentrations in purple leaves is three times lower than in blighted leaves (Silva et al. 2015). The findings of Silva and his colleagues suggested that high levels of cercosporin do not change the color of leaves to purple; instead, it damages the leaf blade, causing necrosis and blight. Their work also suggested that the purple CLB leaf symptom is not caused by a direct accumulation of cercosporin but it may be a plant response reaction to low levels of toxin produced by the pathogen (Silva et al. 2015).

Plant response to biotic and abiotic stresses is a complex mechanism that involves the production of a number of secondary metabolites such as flavonoids, isoflavonoids, carotenoids, anthocyanins, and coumestans (Beggs et al. 1985; Christie et al. 1994; Dixon and Paiva 1995; Dixon et al. 1995, 2002; Grayer and Kokubun 2001; Hahlbrock 1981; Harborne 1999; Li et al. 1993; Lois 1994; Lozovaya et al. 2004; Lygin et al. 2009, 2013; Lyngkjær and Carver 1999; Mazza et al. 2000; Paxton 1981; Siupp and Bailey 1977; Subramanian et al. 2005). Many of these compounds are red and purple in color and could be the cause of the purple discoloration in soybean leaves affected by CLB. 
The objective of the present study was to test the hypothesis that the purple symptom of CLB is a plant response. In this work, we identified and characterized compounds and documented biochemical changes in purple, blighted, and asymptomatic leaves of soybean plants affected by CLB.

Knowing what metabolic pathways in soybean leaves are being triggered in purple leaves as compared with blighted and asymptomatic leaves is essential to our understanding of symptomatology of this important disease. In addition, this knowledge could assist breeders in the development of resistant soybean cultivars.

\section{MATERIALS AND METHODS}

All chemicals and reagents were purchased from Sigma-Aldrich (St. Louis, MO), unless otherwise indicated. All chromatographic solvents were high-performance liquid chromatography (HPLC) grade. All standards of glyceollin, lutein (LUT), $\beta$-carotene $(\beta C A R)$, caffeic acid, feluric acid, gallic acid (GA), transcinnamic acid, quercetin, quercitein, glycitein, and daidzin were used at $1 \mathrm{mg} / \mathrm{ml}$ for identification of compounds in plant extracts with HPLC. Glyceollins, caffeic acid, feluric acid, GA, transcinnamic acid, quercetin, quercitein, glycitein, and daidzin were purchased from ChromaDex, Inc. (Irvine, CA). Standard of coumestrol (COU) was purchased from Sigma-Aldrich.

Leaf collections and extractions. Throughout this study, purple leaves refer to discolored leaves with no apparent chlorotic or necrotic areas. Blighted leaves refer to leaves showing obvious necrotic areas; however, only the chlorotic portions of these leaves were excised, ground, and then evaluated for biochemical components. Asymptomatic, purple, and blighted leaves from the soybean cultivar Pioneer P49T09 BR (DuPont Pioneer, Johnston, IA) were collected at the Louisiana State University Agricultural Center (LSU AgCenter) Dean Lee Research Station in Alexandria, LA in September 2016. Asymptomatic, purple, and blighted leaves from the cultivar Croplan R2C5081 (Winfield Solutions, LLC, Minneapolis, MN) were collected at the LSU AgCenter Research Station in Alexandria, LA in September 2015. Additionally, asymptomatic, purple, and blighted leaves from the soybean cultivar Terral 56R53 (Terral Seed, Inc., Rayville, LA) were collected in Batchelor, LA in September 2015. None of the cultivars used in this work was inoculated and disease pressure relied on natural infection. Croplan R2C5081 was chosen for detailed analyses because it showed consistent disease severity across multiple years in the mid-south of the United States (unpublished data). The cultivars Pioneer P49T09 and Terral 56R53 were chosen because they showed both purple and blight symptoms at the locations where the leaves were collected. Leaves were kept in sealed plastic bags in dry ice until storage at $-30^{\circ} \mathrm{C}$.

In the initial phase of the project, several solvent systems for leaf extraction were tested by thin-layer chromatography (TLC) and HPLC. The chemical profiles of purple, blighted, and asymptomatic leaves were compared for each solvent system tested. Once differences among them were identified, the solvent system was optimized in order to maximize the extraction of compounds of interest. Details about the compounds analyzed by TLC and HPLC will be discussed below. The optimum solvent system consisted of a 2:1:1 ( $\mathrm{vol} / \mathrm{vol} / \mathrm{vol})$ mixture of hexane, ethanol, and acetone, respectively. Leaf extractions were done as follows. For asymptomatic leaves, a 0.1 - to 0.5 -g fresh weight sample was manually ground with sand (twice the mass of the fresh leaf weight) and anhydrous $\mathrm{MgSO}_{4}$ (same mass as the fresh leaf weight). Anhydrous $\mathrm{MgSO}_{4}$ was used as a drying agent to facilitate the grinding process. For purple leaf samples, symptomatic tissue (purple lesions) was selectively excised, ground, and then used in the analyses. Each of the resulting ground materials was added to 20-ml glass vials containing a 2:1:1 ( $\mathrm{vol} / \mathrm{vol} / \mathrm{vol})$ mixture of hexane, ethanol, and acetone (25 volumes per gram of fresh leaf weight); then, the vials were covered with aluminum foil and sonicated (Bransonic 2510 Ultrasonic Cleaner; Branson
Ultrasonics Corp, Danbury, CT) for $1 \mathrm{~h}$. Temperature was monitored and fluctuated between 25 and $30^{\circ} \mathrm{C}$ during the sonication process. The raw extracts were filtered with a $0.45-\mu \mathrm{m}$ syringe filter and stored in the dark at $-20^{\circ} \mathrm{C}$ until further analyses. Raw extracts, which had different dilution ratios, were used for qualitative TLC analyses. For quantitative analyses, the final concentrations of all raw leaf extracts were diluted and adjusted to $0.0184 \mathrm{~g} / \mathrm{ml}$. These diluted samples were used for HPLC and 2,2-diphenyl-1-picryl-hydrazyl (DPPH) assays (discussed below).

Qualitative TLC profiles of raw extracts, purified leaf fractions, and standard solutions. Qualitative TLC analyses were performed on the raw extracts of leaves of the three soybean cultivars showing purple, blight, and no symptoms as well as on the purified fractions obtained from leaf extracts and standard solutions. Approximately $10 \mu \mathrm{l}$ of each of the test solutions (extracts of asymptomatic, purple, and blighted leaves along with purified fractions and standard solutions) were spotted $1.0 \mathrm{~cm}$ from the base of a normal-phase TLC plate coated with the fluorescence indicator (Silica Gel GF UV254, 10-by-20-cm silica gel, scored to 2.5 by $10 \mathrm{~cm}, 250 \mu \mathrm{m}$; Miles Scientific, Newark, DE) using a 10- $\mu$ l glass capillary pipet. Optimum separation for the test solutions was achieved with a mobile phase consisting of hexane and acetone $(6.5: 3.5, \mathrm{vol} / \mathrm{vol})$. Unless specified, this solvent mixture was used in all TLC analyses. Detection of separated compounds was achieved by visualization of bands under visible and UV light at 254 and $365 \mathrm{~nm}$, respectively. Retention factor $\left(\mathrm{R}_{f}\right)$ values of the separated compounds in the raw extracts, purified fractions, and standards were calculated and compared. $\mathrm{R}_{f}$ was calculated as the measure of the distance from the baseline to the front of the corresponding spot on the TLC plate divided by the distance from the baseline to the solvent front. $\mathrm{R}_{f}$ values of the respective spots for the standards COU, $\beta C A R$, and LUT (in methanol) were matched with $\mathrm{R}_{f}$ values of the bands obtained from raw extracts and purified leaf fractions. Identification of bands with respect to the standard compounds was carried out in three mobile phases consisting of acetone/hexane (6.5: $3.5, \mathrm{vol} / \mathrm{vol})$, chloroform/methanol (7:1, vol/vol), and methanol/ methylene chloride/hexane (5:22:3, vol/vol/vol). Results from TLC are not suitable for quantitative comparisons because the leaf extracts were diluted before spotting, if necessary, to avoid streaking of the bands and to optimize separation of the bands.

Separation of raw extracts of purple leaf symptoms using open-column chromatography. Separation of bands from raw extracts of purple leaves of soybean cultivars Pioneer P49T09 BR, Croplan R2C5081, and Terral 56R53 was carried out under reduced light using a microcolumn with 6-mm internal diameter and 14.5-cm height. The stationary phase was 230 - to 400-mesh silica gel (Natland International Corporation, Morrisville, NC), and the mobile phase was hexane/acetone (6.5:3.5, vol/vol). Purple extract $(2 \mathrm{ml})$ was added to $100 \mathrm{mg}$ of silica gel in a glass petri dish, and the solvent was allowed to evaporate. The silica gel loaded with the raw extract was then transferred to the packed column and eluted with the mobile phase and collected in glass vials. Initial fractions with different colors (fractions 1 to 5) were collected in separate vials based on their colors previously observed in TLC analyses (orange, yellow, dark green, light green, and yellow, respectively). Approximate volumes for the colored fractions were fraction 1: approximately $2 \mathrm{ml}$, fraction 2: approximately $8.5 \mathrm{ml}$, fraction 3: approximately $4.5 \mathrm{ml}$, fraction 4 : approximately $3 \mathrm{ml}$, and fraction 5: approximately $3 \mathrm{ml}$. The next few fractions with no color were collected by visualizing on TLC plates under 365-nm UV light. Fractions 6 to 9, which showed blue fluorescence, were collected in separate vials (each containing $3 \mathrm{ml}$ of solution) and stored at $5^{\circ} \mathrm{C}$. The total volume of the mobile phase used in the procedure was $50 \mathrm{ml}$. Vials were wrapped with aluminum foil to minimize light exposure.

HPLC analyses of diluted leaf extracts, purified leaf fractions, and standard solutions. For chromatographic separation, diluted samples of asymptomatic, purple, and blighted leaves of the three soybean cultivars were analyzed using a Waters 1525 
Separation Module (Waters Corp., Milford, MA) and controlled by Waters Empower 2 software. The separation was performed on a C18 column Symmetry C18 (100 A, 4.6 by $250 \mathrm{~mm}, 5 \mu \mathrm{m})$ by a gradient resulting from mixing eluents, water, and acetone, as described by Blanco et al. (2013). Briefly, an initial composition of $25 \%$ acetone and $75 \%$ deionized water was used. This initial condition was achieved in $5 \mathrm{~min}$. After achieving this initial condition, a sample was injected and allowed to run for another $5 \mathrm{~min}$. Acetone was increased linearly to $95 \%$ in $10 \mathrm{~min}$, then raised to $100 \%$ after $2 \mathrm{~min}$ and held constant for $10 \mathrm{~min}$. Before each sample injection, the column was equilibrated and the initial composition of $25 \%$ acetone and $75 \%$ deionized water was allowed to run for $5 \mathrm{~min}$. For all HPLC analyses, the injection volume was $10 \mu \mathrm{l}$, the flow rate was $1 \mathrm{ml} / \mathrm{min}$, and the range of data acquisition was 210 to $800 \mathrm{~nm}$ using a Waters 2996 photodiode array detector. Identification of peaks was carried out by comparison of retention times (Rt) and absorption spectra of the eluting peaks and standards of LUT, $\beta C A R$, caffeic acid, feluric acid, quercitin, GA, trans cinnamic acid, quercitin, quercitein, glycitein, daidzin, COU, and glyceollin. Standard solutions for calibration curves were prepared for COU in methanol at the following concentrations: 0.5, 1.5, 4.5, $7.5,11.5,14.5,19.5,24.5$, and $27.5 \mu \mathrm{M}$. Absolute quantities of COU in leaf samples were calculated by using an equation derived from the linear regression: COU concentration $=\mathrm{f}($ peak area $)$. Peaks corresponding to chlorophyll $a$ and $b$ and carotenoids were identified by comparing the well-known UV absorption profiles of the pigments (Gross 1991; Lichtenthaler 1987; Porra et al. 1989; Rodriguez-Amaya 2001) and by comparing their Rt with their respective standards.

The ApexTrack peak detection and integration of the Empower software was used to calculate the area of each peak on the chromatograms. The ApexTrack algorithm finds baselines by starting at each peak's apex, expanding a trial baseline downward and outward, then fusing trial baselines to form cluster baselines. The ApexTrack determines the end points of peak and cluster baselines by internal slope comparisons.

Mass spectrometric and nuclear magnetic resonance analyses. Mass spectrometric analyses were performed on an Agilent 6210 ESI-TOF instrument equipped with an Agilent 1200 binary pump in negative electrospray ionization (ESI) mode using MassHunter acquisition software. The ESI source was operated with a capillary voltage of $3,500 \mathrm{~V}$ and gas temperature and flow of $325^{\circ} \mathrm{C}$ and 8 liters/min (nitrogen), respectively. Nebulizer pressure was maintained at 20 psi. The solvent system was $30 \%$ water and $70 \%$ acetonitrile, both containing $0.1 \%$ formic acid. A flow rate of $250 \mu \mathrm{l} / \mathrm{min}$ and a column temperature of $25^{\circ} \mathrm{C}$ were maintained. Standard COU $(0.2 \mu \mathrm{l})$ at a concentration of $4 \mu \mathrm{M}$ and $1 \mu \mathrm{l}$ of the purified fraction 8 (Frac8) were used on the analysis. The column used was a Zorbax, SB-C18 Rapid Resolution Cartridge, 2.1 by $30 \mathrm{~mm}, 3.5-\mu \mathrm{m}$ pore size (part number 873700-902; Agilent Inc.).

${ }^{1} \mathrm{H}$ nuclear magnetic resonance (NMR) spectra were recorded on a $500 \mathrm{MHz}$ Bruker spectrometer. Peak positions were relative to the solvent (methanol) residual peak with tetramethylsilane as a reference. All NMR data were processed with TopSpin software.

Determination of pigment concentrations in leaf tissue by spectrophotometric analyses. Concentrations of total chlorophyll (Chl), chlorophyll $a(\mathrm{Chl} a)$, chlorophyll $b(\mathrm{Chl} b)$, and total carotenoids (corotenes and xanthophylls [CAR]) were estimated as described by Lichtenthaler (1987). Absorbance of raw extracts from asymptomatic, purple, and blighted leaves was recorded from 190 to $700 \mathrm{~nm}$ using a UV Vis spectrophotometer (Beckman Coulter DU 720; Beckman Coulter Inc., Fullerton, CA). The solvent system hexane/ethanol/acetone $(2: 1: 1, \mathrm{vol} / \mathrm{vol} / \mathrm{vol})$ was used as a blank.

Analyses of antioxidant activity of COU and leaf extracts using DPPH. Antioxidant activities of COU and raw extracts from asymptomatic, purple, and blighted leaves from Pioneer P49T09 BR were evaluated using a colorimetric method, as described by Blois (1958), Jeon et al. (2012), and Patel and Patel (2011), with modifications. DPPH is a stable free radical with maximum absorption at $517 \mathrm{~nm}$ (purple color). Upon reaction with antioxidants, DPPH is reduced to DPPHH (1-diphenyl-2picrylhydrazine) (yellow color), causing a reduction in absorption at $517 \mathrm{~nm}$. Solutions of GA in methanol at 2, 10, 20, 40, 60, 80, and $100 \mu \mathrm{M}$ were used as positive controls and as references for antioxidant activity for COU. Briefly, $3 \mathrm{ml}$ of COU at 2, 10, 20, 40, 60,80 , and $100 \mu \mathrm{M}$ were prepared using $100 \%$ methanol. DPPH ( $1 \mathrm{ml}$ of $0.1 \mathrm{mM}$ ) in methanol was added to each of the samples. The blank solution was $4 \mathrm{ml}$ of pure methanol. For the negative control, $1.0 \mathrm{ml}$ of $0.1 \mathrm{mM}$ DPPH was added to $3 \mathrm{ml}$ of methanol. The mixtures were homogenized by vortexing the test tubes for $10 \mathrm{~s}$, and they were then allowed to stand in the dark for $30 \mathrm{~min}$ at room temperature. The reduction in absorbance at $517 \mathrm{~nm}$ was measured using a UV-VIS spectrophotometer. Free radical scavenging effect (SE) of $\mathrm{COU}$ and GA were calculated as follows: \% $\mathrm{SE}=$ ([absorbance of negative control] - [absorbance of test sample])/ (absorbance of negative control) $\times 100$.

Effect of COU on growth of $C$. cf. flagellaris in agar media. Potato dextrose agar (PDA) and V8 agar were prepared as described by Weiss (1957) and amended with COU solubilized in $1 \mathrm{ml}$ of methanol to make final concentrations of 19 and $190 \mu \mathrm{M}$. Control treatments had $1 \mathrm{ml}$ of methanol added without COU to $300 \mathrm{ml}$ of PDA and V8. The isolates of $C$. cf. flagellaris used in this experiment (DLL6013-1B, NRL6020-2B, and 2011-90) were recovered by G. Cai (Cai and Schneider 2005). Three 4-mmdiameter plugs of each isolate were ground with autoclaved distilled water in a glass tissue grinder, and one droplet of this suspension was placed in the center of each plate. The number of replications for each treatment is shown in Table 1 . The cultures were incubated in a light chamber at $25^{\circ} \mathrm{C}$ with a fluorescent light regime of $12 \mathrm{~h}$ of light and $12 \mathrm{~h}$ of darkness. Colony diameters were measured after $5,10,15$, and 25 days.

Data analysis. Tukey's post hoc multiple comparison tests $(P<$ $0.01)$ were used for mean separations using Minitab Statistics Software (version 17.3.1; Minitab, State College, PA) for the following analyses: amounts of pigments in asymptomatic, purple, and blighted leaves; SE of standard solutions of COU and GA; and concentrations of COU in asymptomatic, purple, and blighted leaves. For the quantification of leaf pigments, Tukey's post hoc multiple comparison test $(P<0.05)$ was used.

TABLE 1. Radial growth of Cercospora cf. flagellaris 25 days after inoculation into coumestrol (COU)-amended potato dextrose agar (PDA) and V8 agar (V8) in 9-cm petri dishes ${ }^{\mathrm{x}}$

\begin{tabular}{lcccc}
\hline \multirow{2}{*}{ Isolate } & Medium & $\begin{array}{c}\text { Concentration of } \\
\text { COU }(\mu \mathrm{M})^{\mathrm{y}}\end{array}$ & $N^{\mathrm{z}}$ & Colony diameter $(\mathrm{mm})$ \\
\hline 2011-90 & PDA & Control & 4 & $26.5 \pm 3.0 \mathrm{a}$ \\
& & 190 & 5 & $25.4 \pm 0.9 \mathrm{a}$ \\
& & 19 & 5 & $27.4 \pm 3.6 \mathrm{a}$ \\
& V8 & Control & 5 & $28.4 \pm 0.9 \mathrm{a}$ \\
& & 190 & 4 & $29.0 \pm 0.4 \mathrm{a}$ \\
DLL 6013 1B & PDA & 19 & 3 & $26.3 \pm 0.9 \mathrm{a}$ \\
& & Control & 6 & $45.3 \pm 7.0 \mathrm{a}$ \\
& & 190 & 6 & $34.3 \pm 2.2 \mathrm{a}$ \\
& & 19 & 4 & $34.0 \pm 2.9 \mathrm{a}$ \\
NRL 6020 2B & Control & 5 & $35.8 \pm 0.8 \mathrm{a}$ \\
& & 190 & 5 & $35.0 \pm 1.9 \mathrm{a}$ \\
& & 19 & 4 & $31.7 \pm 2.0 \mathrm{a}$ \\
& & Control & 6 & $35.8 \pm 7.9 \mathrm{a}$ \\
& & 190 & 6 & $31.6 \pm 2.9 \mathrm{a}$ \\
& & 19 & 5 & $34.2 \pm 8.0 \mathrm{a}$ \\
& & Control & 6 & $27.8 \pm 1.4 \mathrm{a}$ \\
& & 190 & 5 & $37.4 \pm 4.6 \mathrm{a}$ \\
& & 19 & 4 & $28.0 \pm 1.3 \mathrm{a}$ \\
\hline
\end{tabular}

${ }^{\mathrm{x}}$ Means followed by the same letters for each isolate are not significantly different according to Tukey's post hoc multiple comparison test $(P<0.05)$. y Control $=$ not amended with COU.

z Number of replications. 


\section{RESULTS}

Qualitative TLC profiles of raw leaf extracts. TLC plates spotted with raw extracts of asymptomatic, purple, and blighted leaves from the cultivars Pioneer P49T09 BR, Croplan R2C5081, and Terral 56R53 were analyzed under visible and UV lights $(\lambda=$ $365 \mathrm{~nm}$ and $\lambda=254 \mathrm{~nm}$, respectively). Results revealed that the optimum separation for all sample constituents was achieved with the solvent system hexane/acetone (6.5:3.5, vol/vol) (Fig. 1A). Although the TLC analyses were not done for quantification purposes, it was possible to observe differences on the plates under visible and especially UV lights. Bands Car1, Bdc1, Chla, Bdc2, $\mathrm{Chl} b$, Car2, and Car5 were found in both asymptomatic and purple leaves of Pioneer P49T09 BR (Fig. 1B). However, bands Car3 and Car4 were detected as intense bands in purple leaves (Fig. 1B) but as very faint bands in asymptomatic leaves of Pioneer P49T09 BR (Fig. 1B). TLC plates for all extracts of blighted leaves showed only very faint bands for Car2 and Chla (Fig. 1B). Moreover, under visible light, TLC plates of asymptomatic and purple leaves of Croplan R2C5081 showed only bands Chl $a$, Chl $b$, and Car2 (Fig. 1B). Only faint bands were detected on TLC plates from leaf extracts of blighted leaves of this cultivar (Fig. 1B). Chromatograms of leaf extracts from Terral 56R53 were similar to those of Croplan R2C5081 under visible light (Fig. 1B). Under UV light, TLC plates of asymptomatic and purple leaves of the three cultivars consistently showed two intense red-fluorescent bands corresponding to Chl $a$ and $\mathrm{Chl} b$ (Fig. 1B). TLC plates of blighted leaves showed only weak bands for Chla for all three cultivars (Fig. 1B). Three prominent blue-fluorescent bands (UV1, UV2, and UV 3) were consistently found in purple leaves of the three cultivars (Fig. 1B). A very faint UV1 band also was found in asymptomatic leaves of Pioneer P49T09 and blighted leaves of Croplan R2C5081 (Fig. 1B). These faint bands were negligible in intensity when compared with bands found on TLC plates of purple leaves. The $\mathrm{R}_{f}$ values of the blue-fluorescent bands (UV1, UV2, and UV3), found mostly in purple leaf extracts, were calculated and are presented in Table 2.
TLC profiles for pigments of leaf extracts are well known (Lichtenthaler 1987), and identification of these compounds was done using the relative locations of the spots on TLC plates, the color of the pigments under visible and UV lights, and, in some cases (Car1 and Car2), by comparison with TLC and HPLC profiles of standard compounds. Bands were then identified as $\beta$-carotene (Car1), lutein (Car2), xanthophylls (Car3, Car4, and Car5), Chla, pheophytin, $\mathrm{Chl} b$, and possibly breakdown products of chlorophylls (Bdc1 and Bdc2).

HPLC of diluted leaf extracts. HPLC analyses were performed to identify the blue-fluorescent metabolites UV1, UV2, and UV3 and to quantify leaf pigments in asymptomatic and diseased leaves of cultivars Pioneer P49T09 BR, Croplan R2C5081, and Terral 56R53. Rt and absorption spectra of the standards for COU, glyceollin, LUT, $\beta C A R$, caffeic acid, feluric acid, GA, trans cinnamic acid, quercitin, quercitein, glycitein, and daidzin were compared with the eluting peaks from the test samples on the HPLC chromatograms. Only minor differences were observed among HPLC profiles of asymptomatic, purple, and blighted raw extracts for the three cultivars. Thus, only the HPLC chromatograms for Pioneer P49T09 BR are shown (Fig. 2).

Based on comparative analyses of absorption spectra and Rt of peaks on the HPLC chromatograms between the raw extracts and standards, we identified peaks for LUT, $\beta C A R$, Chla, and Chl $b$ using their distinctive absorption spectra and relative Rt (Fig. 2) (Gross 1991; Lichtenthaler 1987; Porra et al. 1989; RodriguezAmaya 2001). HPLC chromatograms showed small quantities of LUT, $\beta C A R, C h l a$, and Chl $b$ in blighted leaves (Fig. 2). In contrast, these pigments were found in higher concentrations in asymptomatic and purple leaves (Fig. 2). The highest levels of LUT, $\beta C A R$, $\mathrm{Chl} a$, and $\mathrm{Chl} b$ were found in asymptomatic leaves (Fig. 2). In addition, further UV-Vis analyses of the leaf extracts were conducted to properly quantify $\mathrm{Chl} a, \mathrm{Chl} b$, and CAR (see below).

Although there were no major qualitative differences among the peaks observed across all raw extracts with different symptoms, the three peaks at Rt1 $=11.9 \mathrm{~min}, \mathrm{Rt} 2=12.2 \mathrm{~min}$, and Rt $3=13.9 \mathrm{~min}$
A

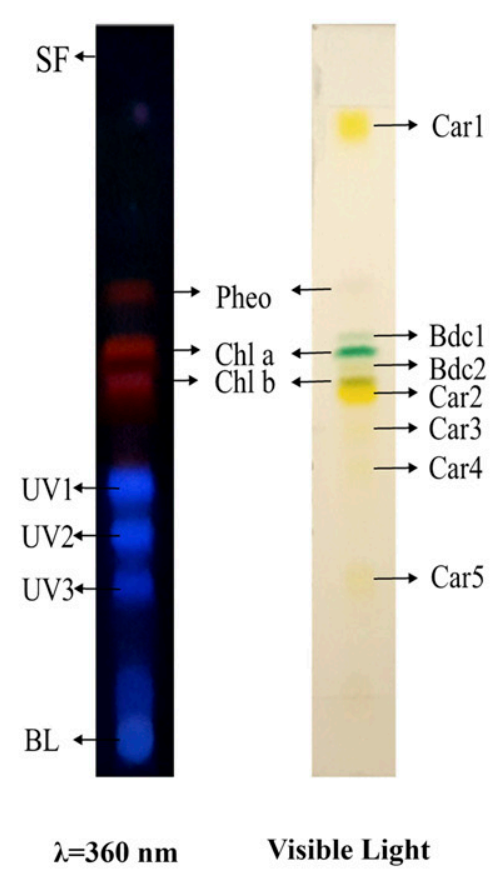

B

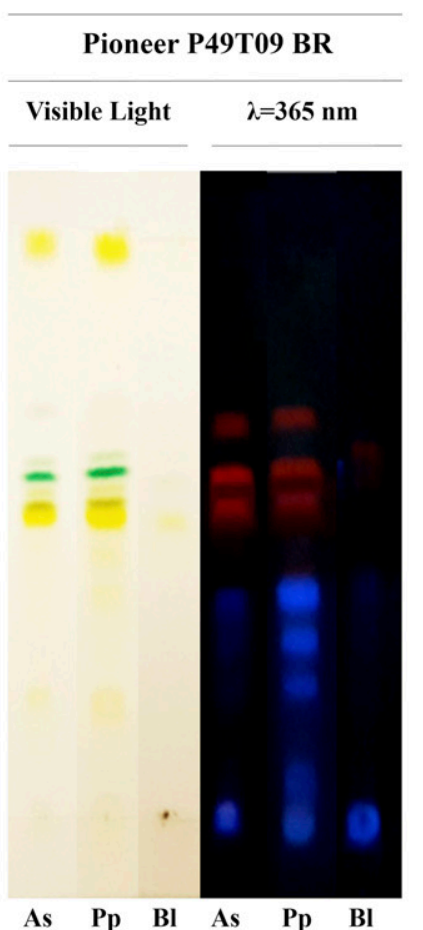

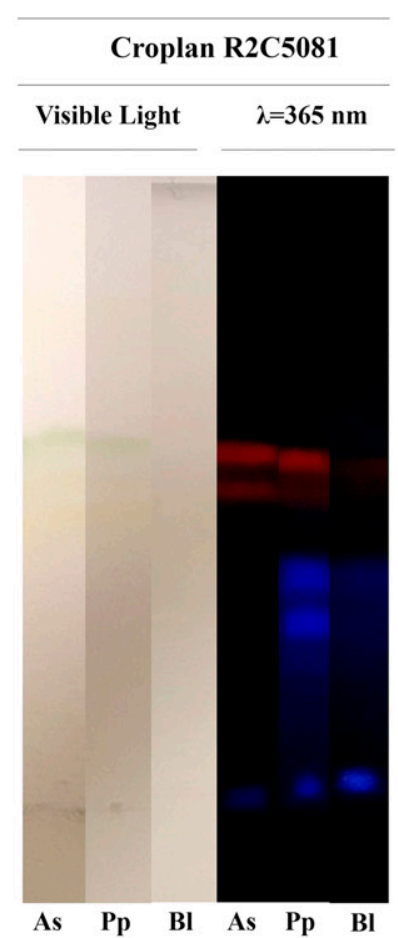

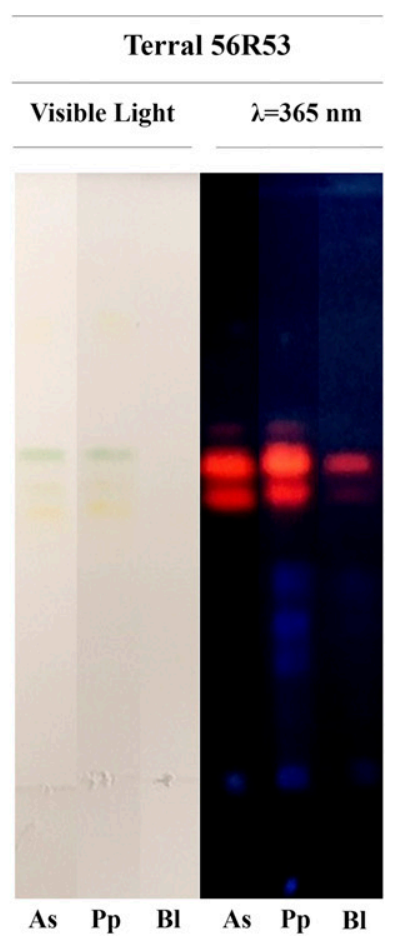

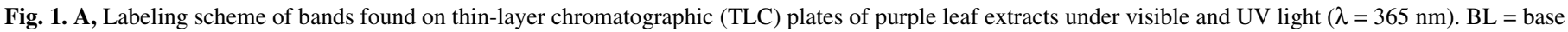

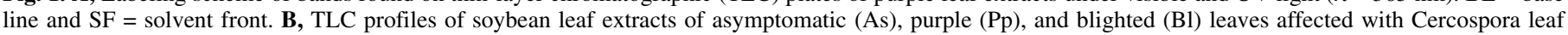

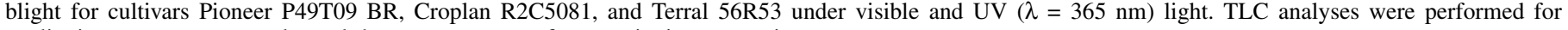
qualitative measurements only, and they are not meant for quantitative comparisons. 
were consistently found in purple leaf extracts analyzed by HPLC at $\lambda=350 \mathrm{~nm}$ (Fig. 2). These three peaks had decreasing trends in peak area in purple, blighted, and asymptomatic extracts, respectively (Fig. 2). These results are in accordance with results from the TLC profiles. Three blue-fluorescent bands were found under UV light $(\lambda=365 \mathrm{~nm})$ on TLC plates (Fig. 1), and three peaks with maximum absorbance in the UV range were detected by HPLC (Fig. 2).

In order to identify the three UV-active peaks that predominated in extracts of purple leaves, comparative HPLC analyses were conducted against standard solutions of the compounds mentioned previously. Our results revealed that the peak at $\mathrm{Rt}=12.2 \mathrm{~min}$ matched the peak for the standard solution of COU (Figs. 2 and 3A). However, other peaks at Rt $=11.9 \mathrm{~min}$ and $\mathrm{Rt}=13.9 \mathrm{~min}$ did not match any of the standard compounds used. Hence, we decided to focus only on the peak at $\mathrm{Rt}=12.2 \mathrm{~min}$.

Identification of the compound responsible for the UV2 band. To identify the compound responsible for the UV2 band, raw extracts from purple leaves of Pioneer P49T09 BR were fractionated using open-column chromatography. A sample of each fraction was analyzed on TLC plates under visible and UV light ( $\lambda=254$ and $365 \mathrm{~nm}$, respectively). Among the fractions eluted from the column (fractions 5, 6, 7, 8, and 9), Frac8 showed the most intense blue-fluorescent UV2 band under long-wave illumination. Multiple analytical techniques (described below) were used to identify the compound present in Frac8 responsible for the UV2 band.

Analysis of Frac8 by HPLC. HPLC analysis of Frac 8 at $\lambda=$ $365 \mathrm{~nm}$ showed a prominent peak at $\mathrm{Rt}=12.2 \mathrm{~min}$, the same Rt as the standard for COU (Fig. 3A). In addition, the maximum absorbance of peaks at $12.2 \mathrm{~min}$ on the HPLC chromatogram matched the maximum absorbance for the COU standard with $\mathrm{UV}_{\mathrm{MeOH}} \lambda_{\text {max }}$ $\mathrm{nm}$ : absorbance for COU of 242, 287, and $340 \mathrm{~nm}$ (Fig. 3A). These results suggested that the UV-active compound with a peak at $12.2 \mathrm{~min}$ in purple leaves of the three soybean cultivars was COU, and it was the major UV-active compound present in Frac8 (Fig. 3A).

Analysis of Frac8 by TLC. TLC analyses with hexane/ acetone $(3.5: 6.5, \mathrm{vol} / \mathrm{vol})$ showed that Frac 8 had a blue-fluorescent band at $\mathrm{R}_{f}=0.28$, which corresponded to the UV2 band observed in raw extracts of purple leaves (Fig. 3B; Table 3). This suggests that the compound responsible for UV2 was present in high concentration in Frac8. Further comparisons of the TLC profiles of Frac8, raw extract of Pioneer P49T09 BR, and the COU standard were carried out in three different solvent systems. The resulting identical $\mathrm{R}_{f}$ values confirmed the identification of the compound responsible for the UV2 band as COU (Table 3).

Mass spectrometric analysis of Frac8 and standard COU. For confirmation of the identity of the UV2 band, mass spectrometric data in negative ESI mode were obtained for Frac8 and compared with the COU standard (Fig. 4). Results showed absolute matches of Frac8 (Fig. 4A and B) and the COU standard (Fig. 4C and D), providing very strong evidence for the presence of COU in Frac8. ESI-MS m/z: [M-H] $]^{-}$calculated for $\mathrm{C}_{15} \mathrm{H}_{8} \mathrm{O}_{5}$, 268.0372, found 268.0374. The Mass Hunter software matched the isotope distribution pattern for this formula in negative mode with a $99.42 \%$ mass match.

Results from TLC, HPLC, and mass spectroscopy (MS) analyses confirmed that the UV2 band was COU. Identification of UV1 and UV3 is in progress, and will be the subject of future publications. NMR spectra for the standard solution of COU in methanol and Frac8 showed similar peaks: ${ }^{1} \mathrm{H}$ NMR signals (ppm) $\mathrm{MeOD}=7.87$ $(\mathrm{d}, 1 \mathrm{H}), 7.76(\mathrm{~d}, 1 \mathrm{H}), 7.10(\mathrm{~s}, 1 \mathrm{H}), 6.69(\mathrm{~d}, 1 \mathrm{H}), 6.68(\mathrm{~d}, 1 \mathrm{H})$, and $6.88(\mathrm{~s}, 1 \mathrm{H})$. However, Frac8 also showed ${ }^{1} \mathrm{H}$ NMR peaks for other unknown compounds. These peaks from unknown NMR compounds are in accordance with results from ESI-MS analysis in which additional peaks other than COU were detected.

Quantification of COU. To validate the qualitative analysis done using TLC, HPLC, and MS analysis, COU was quantified in diluted samples of asymptomatic, purple, and blighted leaf extracts from cultivars Pioneer P49T09 BR and Croplan R2C5081. An equation derived from linear regression (COU concentration $=$ $\mathrm{f}$ [peak area]) using COU standards was used to estimate concentrations of COU in leaves (Fig. 5). The concentration of COU in asymptomatic leaves was statistically lower compared with purple and blighted leaves in both cultivars (Fig. 6A and B). The highest concentration of COU was found in purple leaves (Fig. 6A and B). Moreover, blighted leaves had levels of COU higher than asymptomatic leaves but significantly lower than purple leaves (Fig. 6A and B). In general, the levels of COU in asymptomatic, purple, and blighted leaves of the Croplan R2C5081 were aproximatly 10 times higher than COU levels in leaves of Pioneer P49T09 BR. The concentration of COU in purple leaves of Pioneer P49T09 BR $(2.24 \mu \mathrm{M})$ (Fig. 6B) was lower than in asymptomatic leaves of the Croplan R2C5081 (3.05 $\mu \mathrm{M})$ (Fig. 6A).

HPLC analyses were performed immediately after extraction and after 20 days of extraction to ensure that all of the COU was extracted from the leaves. Leaf extracts from Croplan R2C5081 had substantially higher COU after 20 days as compared with leaf extracts analyzed immediately after the extraction. There were no differences in COU concentrations in leaf extracts of Pioneer P49T09 BR after 20 days. For both cultivars tested, concentrations of COU were significantly higher in purple leaves at both extraction times. The data presented above and shown in Figure 6 describe the results of COU quantification at 20 days.

Location-dependent concentration of $\mathrm{COU}$ in soybean leaves. Concentrations of $\mathrm{COU}$ also were analyzed in symptomatic and asymptomatic areas of single purple and blighted leaves using TLC and HPLC. Portions of the symptomatic areas of purple leaves were collected from the distal ends of leaves where the purple pigmentation was more intense (Fig. 7C). In blighted leaves, portions of symptomatic areas were collected from the chlorotic areas (Fig. 7H). Necrotic areas were not used. Basal areas of purple and blighted leaves where symptoms were not visible (Fig. 7C and $\mathrm{H}$ ) and both distal and basal areas of asymptomatic leaves were used as controls (Fig. 7M).

TLC analyses of raw extracts of different areas of asymptomatic, purple, and blighted leaves, as described above, showed that COU was present only in the purple areas of purple leaves (Fig. 7B). The asymptomatic areas of purple and blighted leaves, as well as the two areas of the asymptomatic leaves, did not show any blue-fluorescent bands (Fig. 7D, G, I, L, and N). In agreement with the TLC results, HPLC analyses detected COU only in extracts obtained from the purple areas of purple leaves (Fig. 7A). No COU was detected by HPLC in any of the other extracts (Fig. 7E, F, J, K, and O). Additionally, visual (Fig. 8A and B) and microscopic (Fig. 8C) analysis of freehand-cut leaves of soybean plants showed that purple symptoms of CLB are present only in in adaxial surfaces of leaves in the upper canopy of soybean plants.

TABLE 2. Retention factor $\left(\mathrm{R}_{f}\right)$ values for UV1, UV2, and UV3 bands (bluefluorescent bands under UV light, $\lambda=365 \mathrm{~nm}$ ) found on thin-layer chromatography plates of asymptomatic, purple, and blighted leaves of soybean cultivars Pioneer P49T09 BR, Croplan R2C5081, and Terral 56R53 affected by Cercospora leaf blight

\begin{tabular}{llccc}
\hline & & \multicolumn{3}{c}{$\mathrm{R}_{f}$ values } \\
\cline { 3 - 5 } Soybean cultivar & Leaf symptom & $\mathrm{UV1}$ & $\mathrm{UV2}$ & $\mathrm{UV3}$ \\
\hline Pioneer P49T09 BR & Asymptomatic & 0.37 & $\ldots$ & $\ldots$ \\
& Purple & 0.37 & 0.28 & 0.22 \\
Croplan R2C5081 & Blight & $\ldots$ & $\ldots$ & $\ldots$ \\
& Asymptomatic & $\ldots$ & $\ldots$ & $\ldots$ \\
Terral 56R53 & Purple & 0.37 & 0.28 & 0.22 \\
& Blight & 0.37 & $\ldots$ & $\ldots$ \\
& Asymptomatic & $\ldots$ & $\ldots$ & $\ldots$ \\
& Purple & 0.37 & 0.28 & 0.22 \\
& Blight & $\ldots$ & $\ldots$ & $\ldots$ \\
\hline
\end{tabular}


Quantification of leaf pigments. Even though COU was found in purple symptoms of leaves affected by CLB, these findings did not explain the basis for purple discoloration because COU is a colorless compound. Our previous findings suggested that purple pigmentation is not related to anthocyanins (data not shown). We hypothesize that the purple leaf discoloration is caused by the accumulation of CAR, the reduction of Chl content, or a combination of both, which would make CAR more visible in leaves. High levels of $\mathrm{Chl} a$, $\mathrm{Chl} b$, and Chl were found in asymptomatic leaves of Pioneer P49T09 BR (Fig. 9A, B, and C). The
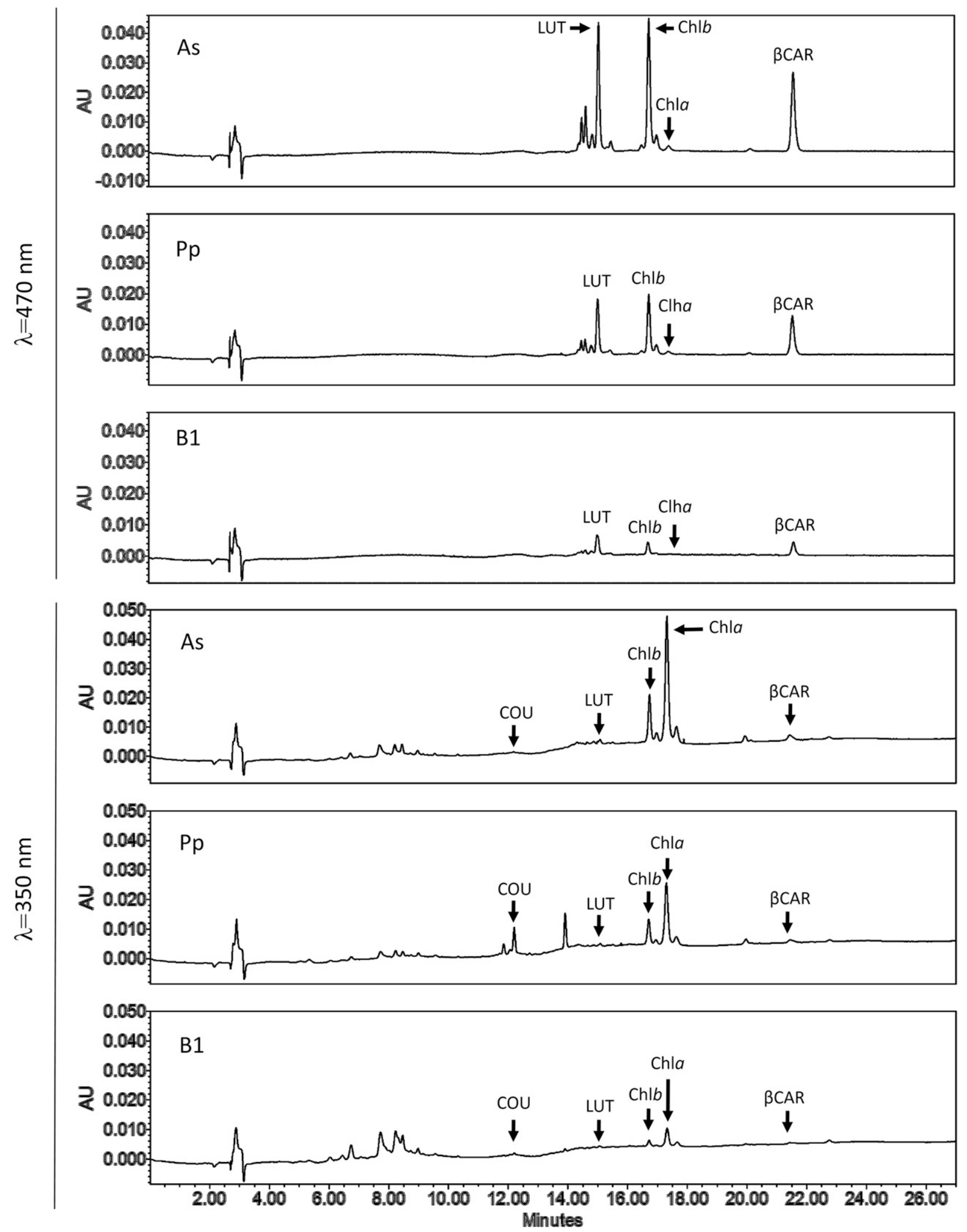

Fig. 2. High-performance liquid chromatographic profiles of extracts of asymptomatic (As), purple (Pp), and blighted leaves (Bl) of the soybean cultivar Pioneer P49T09 BR affected by Cercospora leaf blight at $\lambda=470$ and $350 \mathrm{~nm}$. Peak: COU $=$ coumestrol, LUT $=$ lutein, Chl $b=$ chlorophyll $b$, Chl $a=$ chlorophyll $a$, and $\beta C A R=\beta$ carotene. Experiment was repeated once with similar results. 
level of Chla was significantly higher in asymptomatic leaves as compared with purple leaves (Fig. 9A). However, concentrations of $\mathrm{Chl} b$ and $\mathrm{Chl}$ in asymptomatic and purple leaves were not statistically different (Fig. 9B and C). Chla, Chl b, and Chl were significantly lower in blighted leaves as compared with asymptomatic leaves (Fig. 9A, B, and C). Only Chl b was not significantly lower in blighted as compared with purple symptom area of the leaves (Fig. 9A, B, and C).

Concentrations of CAR were significantly higher in asymptomatic as compared with blighted leaves but CAR levels in purple leaves were not significantly different from asymptomatic and blighted leaves (Fig. 9D). Moreover, there were no significant differences in the ratios of Chl $a$ to $\mathrm{Chl} b$ in asymptomatic, purple, and blighted leaves (Fig. 9E). However, the ratio of CAR to Chl was significantly higher in blighted leaves than in asymptomatic and purple leaves (Fig. 9F). A similar trend was observed in the levels of Chl $a$, Chl $b$, Chl, CAR, Chla/Chl $b$, and CAR/Chl in the cultivars Croplan R2C5081 and Terral 56R53.

DPPH assay for radical scavenging activity. The radical scavenging activities of standard COU solutions and soybean leaf extracts were assessed as described above. Solutions of COU at concentrations of $2,10,20,40,60,80$, and $100 \mu \mathrm{M}$ in methanol were used in the analyses. Because the quantification of COU on Pioneer P49T09 BR and Croplan R2C5081 was done in diluted samples (Fig. 6A and B), a higher concentration of COU was used for the DPPH assay to compensate for the dilution factor and to provide an estimate of the antioxidant potential of COU in leaves. GA at the same concentrations as COU was used as the positive control. Results were recorded at $30 \mathrm{~min}$.

A graded increase in SE was observed as the concentration of COU increased (Table 4). In contrast, SE of concentrations of GA above $60 \mu \mathrm{M}$ reached a plateau of approximately $90 \%$ after $30 \mathrm{~min}$ of reaction (Table 4). Solutions of $100 \mu \mathrm{M}$ COU showed $55.5 \%$ less $\mathrm{SE}$ as compared with GA at the same concentration and time of reaction $(30 \mathrm{~min})$.

Effect of COU on growth of $\boldsymbol{C}$. cf. flagellaris. There were no significant differences in growth of three isolates of $C$. cf. flagellaris in PDA or V8 agars amended with 19 or $190 \mu \mathrm{M} \mathrm{COU}$ after 5, 10, 15, and 25 days (Table 1).

\section{DISCUSSION}

Results from analyses of pigments in asymptomatic, purple, and blighted soybean leaves affected by CLB showed reductions in concentrations of Chl $a, \mathrm{Chl} b, \mathrm{Chl}$, and CAR in blighted compared with purple leaves. Chlorotic as opposed to necrotic areas of blighted leaves were sampled. As expected, concentrations of these pigments were greater in asymptomatic portions of leaves, showing that blighted areas of leaves were undergoing more severe stress as compared with purple areas. These findings support results from a previous study that showed that biomass of $C$. cf. flagellaris and cercosporin concentrations were significantly higher in blighted leaves (Silva et al. 2015). The high concentrations of Chla, Chl b, $\mathrm{Chl}$, and CAR in asymptomatic leaves reflect the reduced damage caused by $C$. cf. flagellaris in its endophytic stages. The ratios of Chl $a$ to $\mathrm{Chl} b$ in asymptomatic, purple, and blighted leaves were not statistically different, suggesting that the reduction of Chla and Chl $b$ occurs at the same rate. Previous researchers showed reductions in leaf pigments related to disease stress in several crop species (Scarpari et al. 2005; Zhao et al. 2016). Zhao et al. (2016) showed that the levels of Chl $a$ and Chl $b$ were reduced along with the severity of angular leaf spot caused by the bacterium Pseudomonas

TABLE 3. Retention factors $\left(\mathrm{R}_{f}\right)$ of coumestrol (COU) standards and of the UV2 band from purple leaf extracts of the soybean cultivar Pioneer P49T09 BR affected by Cercospora leaf blight and fraction 8 obtained from the crude extract of purple leaves ${ }^{\mathrm{z}}$

\begin{tabular}{lll}
\hline Solvent ratio & \multicolumn{1}{c}{ Sample } & \multicolumn{1}{c}{$\mathrm{R}_{f}$} \\
\hline Acetone/hexane (3.5:6.5) & COU standard & 0.28 \\
& UV2 (purple leaves) & 0.28 \\
& Fraction 8 & 0.28 \\
Methanol/chloroform (1:7) & COU standard & 0.5 \\
& UV2 (purple leaves) & 0.5 \\
Methanol/methylene chloride/hexane (5:22:3) & COU standard & 0.89 \\
& UV2 (purple leaves) & 0.89 \\
\hline
\end{tabular}

$\mathrm{z}$ Thin-layer chromatography of the samples was run with three different solvent systems. Bands for the COU standard and UV2 were identified under UV light $(\lambda=365 \mathrm{~nm})$.
A
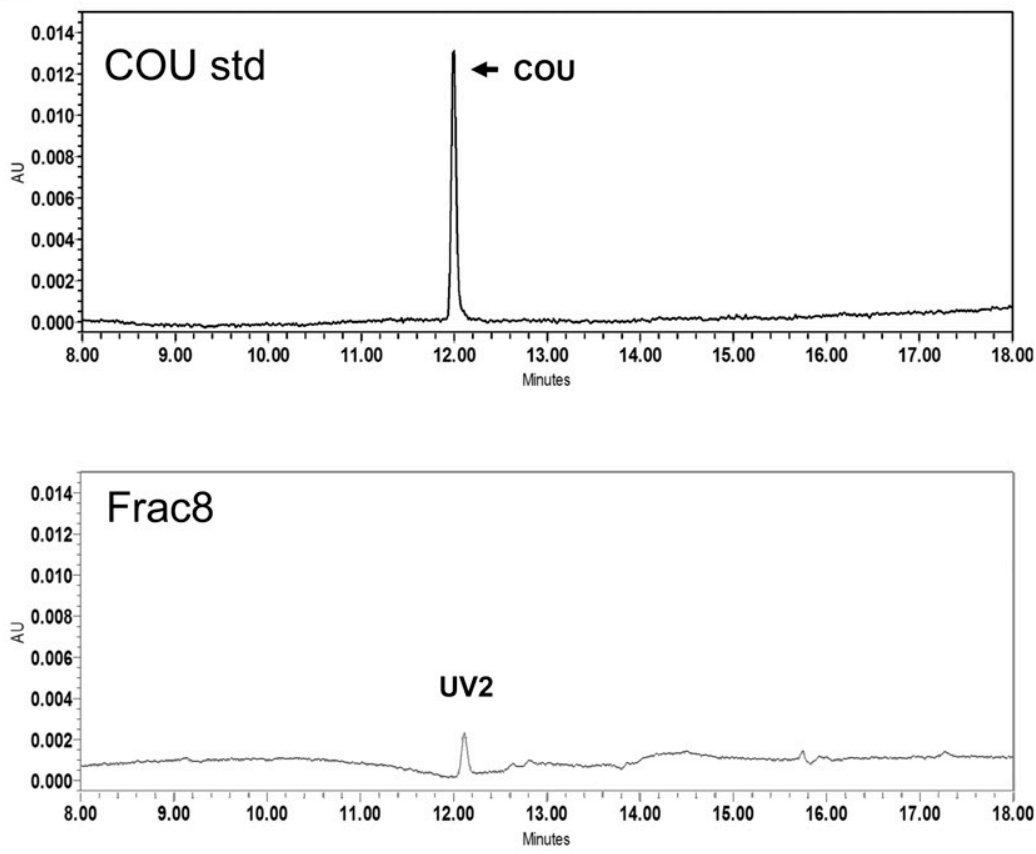

B

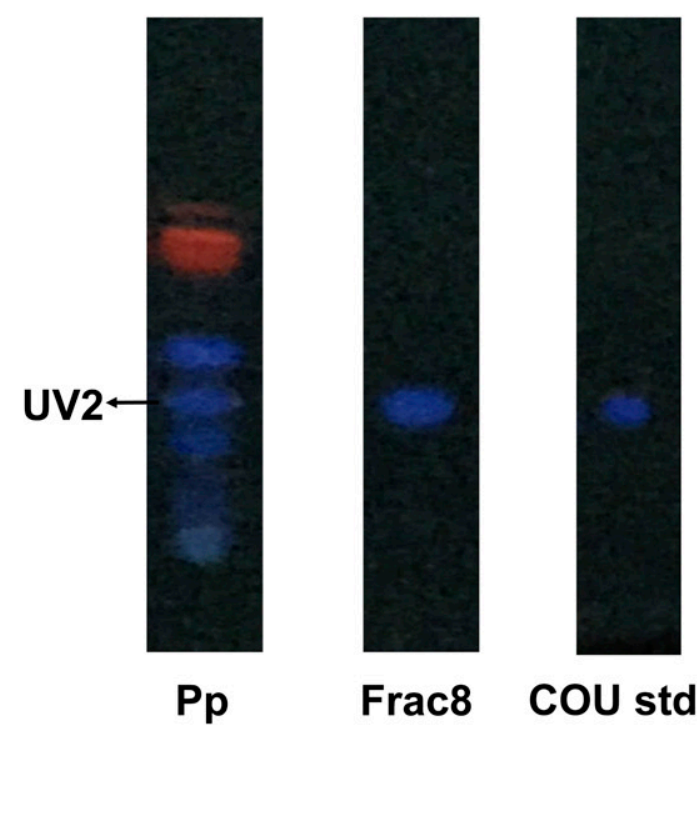

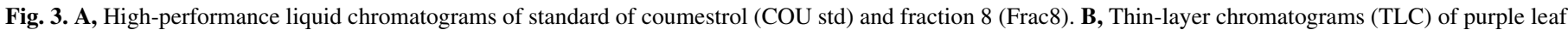
extracts of soybean cultivar Pioneer P49T09 BR affected by Cercospora leaf blight (Pp), Frac8, and COU std. 
syringae pv. lachrymans in cucumber. Moreover, Chla and Chlb were lower throughout the development of the witches' broom disease in cocoa caused by the fungus Crinipellis perniciosa (Scarpari et al. 2005). Carotenoids and xanthophylls also were reduced in infected tissue during symptom development.

The lower levels of CAR and higher values for the CAR/Chl ratio in blighted as compared with asymptomatic and purple leaves does not support the hypothesis that the purple pigmentation is the result of CAR accumulation or the reduction of the Chl background color. In addition, the higher ratio of CAR to $\mathrm{Chl}$ is an important indication of physiological imbalance in chloroplasts of purple and, especially, blighted leaves. This physiological stress may be related to intense light and high levels of damaging cercosporin found in blighted leaves. Photosynthetic organisms such as soybean require light for growth. However, excessive light can be harmful and lead to photooxidative damage and photoinhibition caused by accumulation of ROS (Erickson et al. 2015). ROS induced by light-activated cercosporin may intensify photooxidative damage and photoinhibition in blighted leaves and cause reductions in Chl content. Higher levels of CAR may protect asymptomatic and purple leaves by scavenging ROS and quenching triplet-state Chl (Young 1991).

Our findings not only provide the first report of accumulation of COU in purple leaves of soybean affected by CLB but also demonstrate that COU may be associated with resistance to Cercospora cf. flagellaris via its antioxidant activity. In addition, we found two other blue-fluorescent bands in our TLC plates that were associated with the purple symptom; however, these bands have yet to be identified. COU is a flavonoid in the coumestan group that is found in leguminous plants, including alfalfa, white clover, lima bean, split pea, and soybean (Mostrom and Evans 2011). Biosynthesis of COU is derived from daidzein in the phenylpropanoid pathway (Mostrom and Evans 2011). In leguminous plants, COU is a compound that is often associated with biotic stresses such as those induced by Colletotrichum gloeosporioides, Pratylenchus scriberni (Rich et al. 1977), Aspergillus sojae (Boué et al. 2000), A. oryzae (Jeon et al. 2012), and aphid feeding (Loper 1968). In addition, abiotic stresses such as wounds (Graham and Graham 1996), excess copper (Sherwood et al. 1970), UV

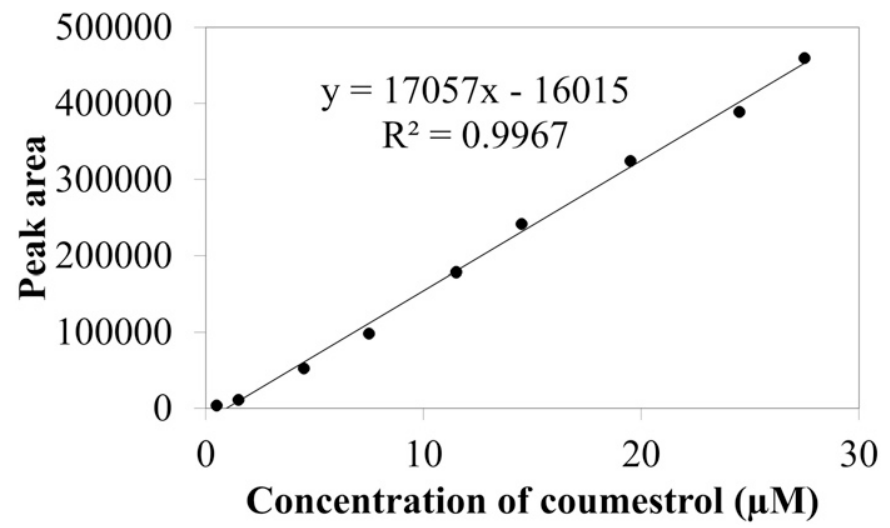

Fig. 5. Standard curve for coumestrol (COU) prepared using known standard COU concentrations. The regression line was generated by linear regression analysis plotting the concentration of $\mathrm{COU}$ on the $\mathrm{X}$ axis versus the area of the COU peak from the high-performance liquid chromatogram on the $\mathrm{Y}$ axis.
A

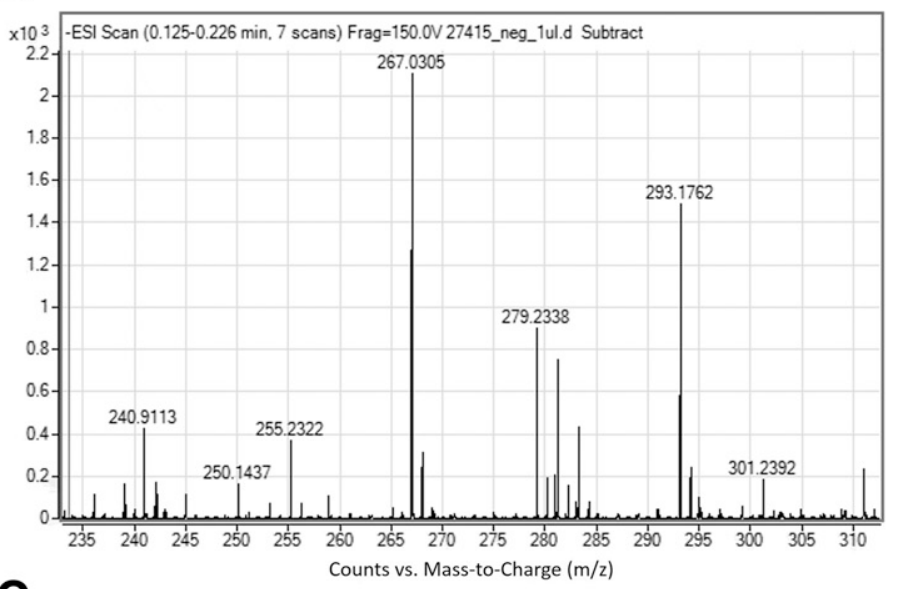

C

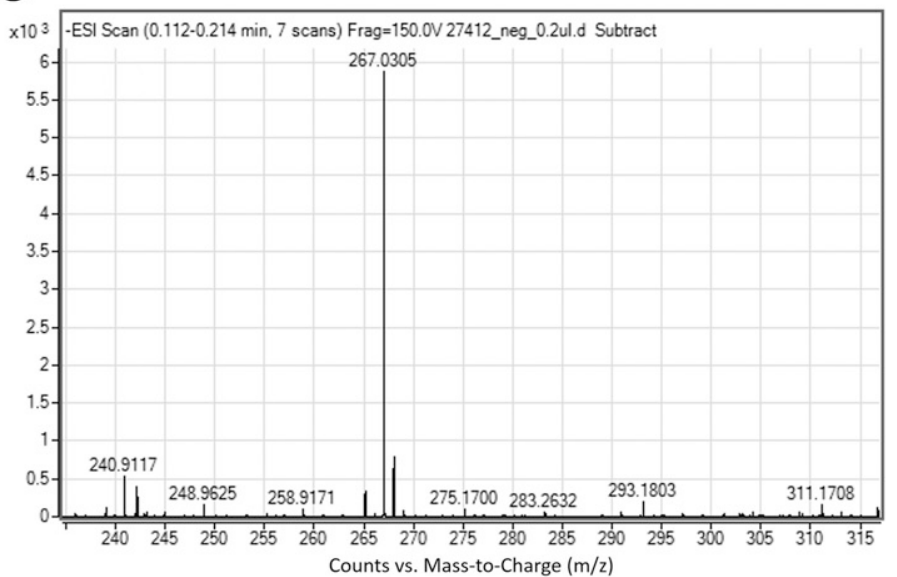

B

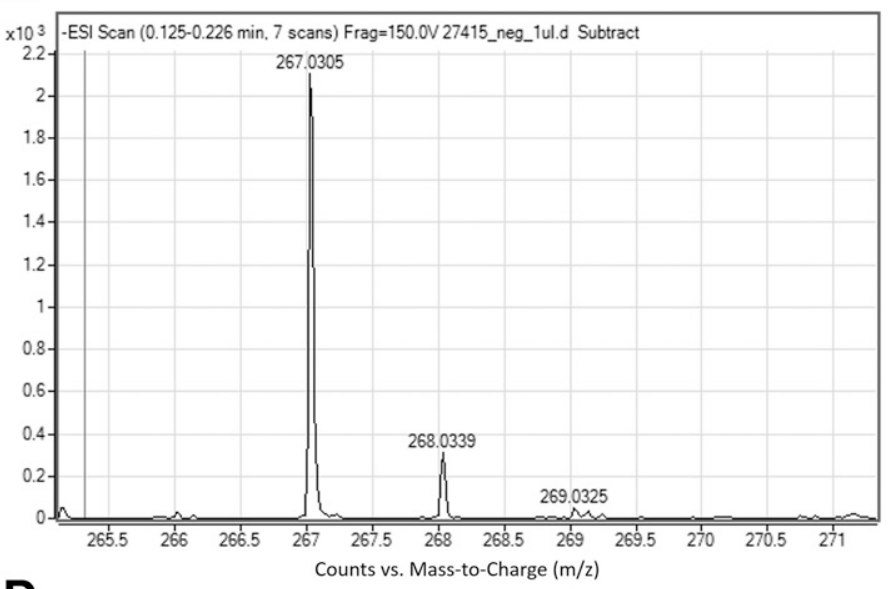

D

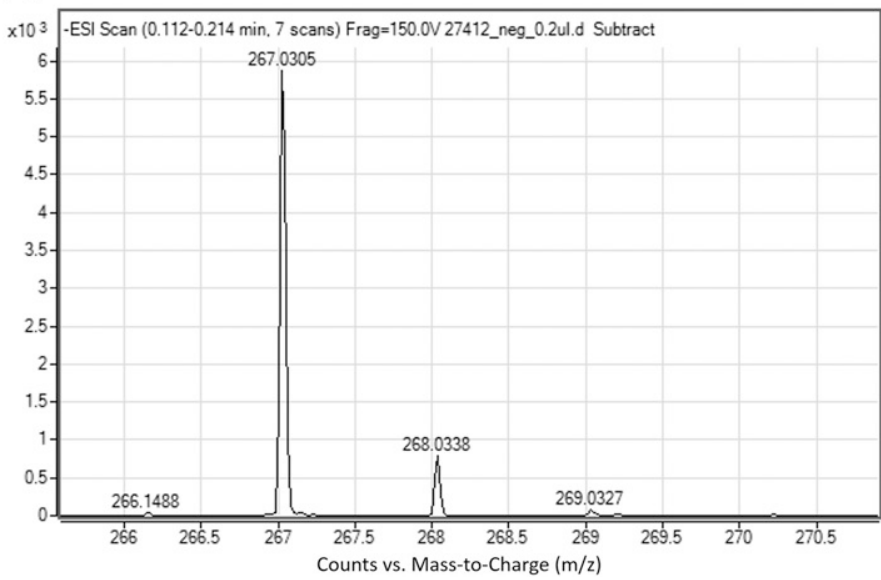

Fig. 4. A, and B, Mass spectroscopy of fraction 8 from extracts of soybean leaves showing the purple symptom of Cercospora leaf blight; and $\mathbf{C}$, and $\mathbf{D}$, coumestrol (COU) standards. B and D are enlargements of A and C, respectively, to show the isotope distribution related to COU. 
A

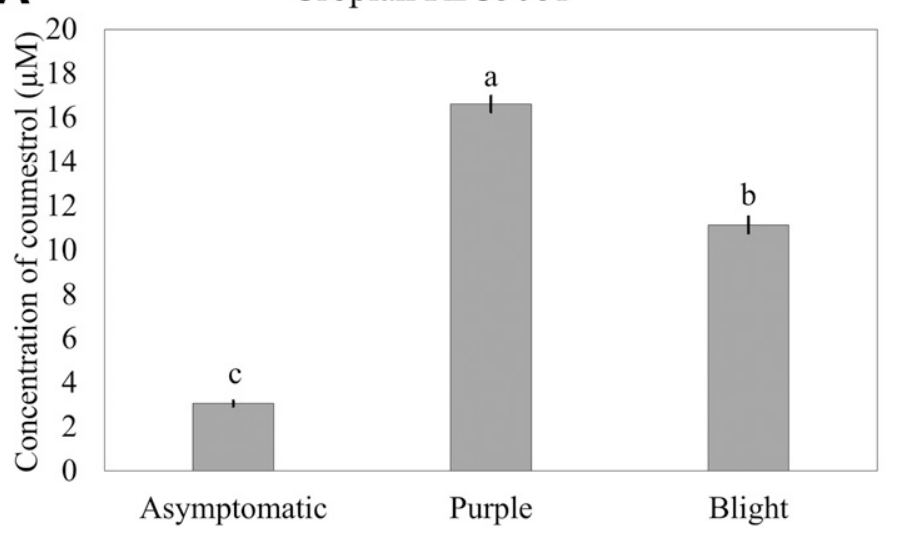

B

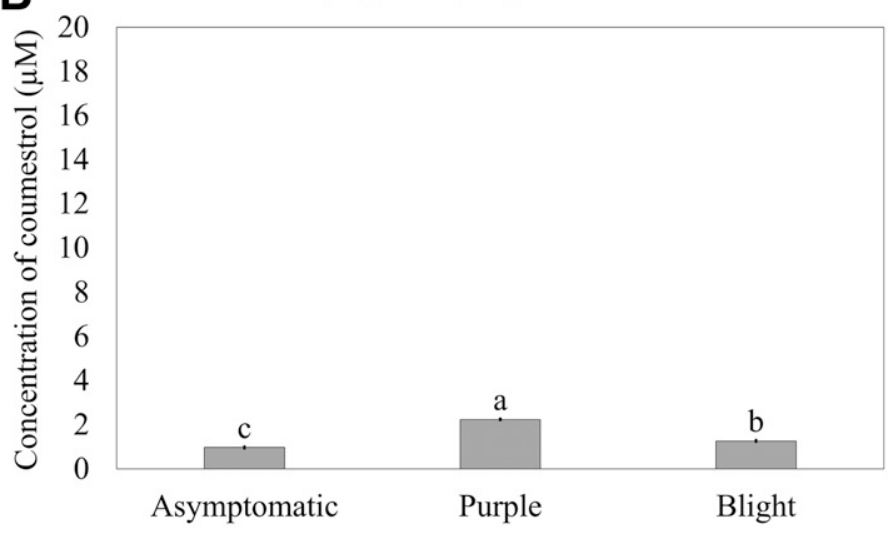

Fig. 6. Concentrations of coumestrol in diluted extracts of asymptomatic, purple, and blighted leaves of the indicated soybean cultivars at 20 days after extraction. A, Croplan R2C5081 and B, Pioneer P49T09 BR affected by Cercospora leaf blight. Means followed by different letters are significantly different by Tukey's post hoc multiple comparison test $(P<0.01)$. Bars indicate standard errors of the mean $(n=3)$. Experiment was repeated once with similar results.
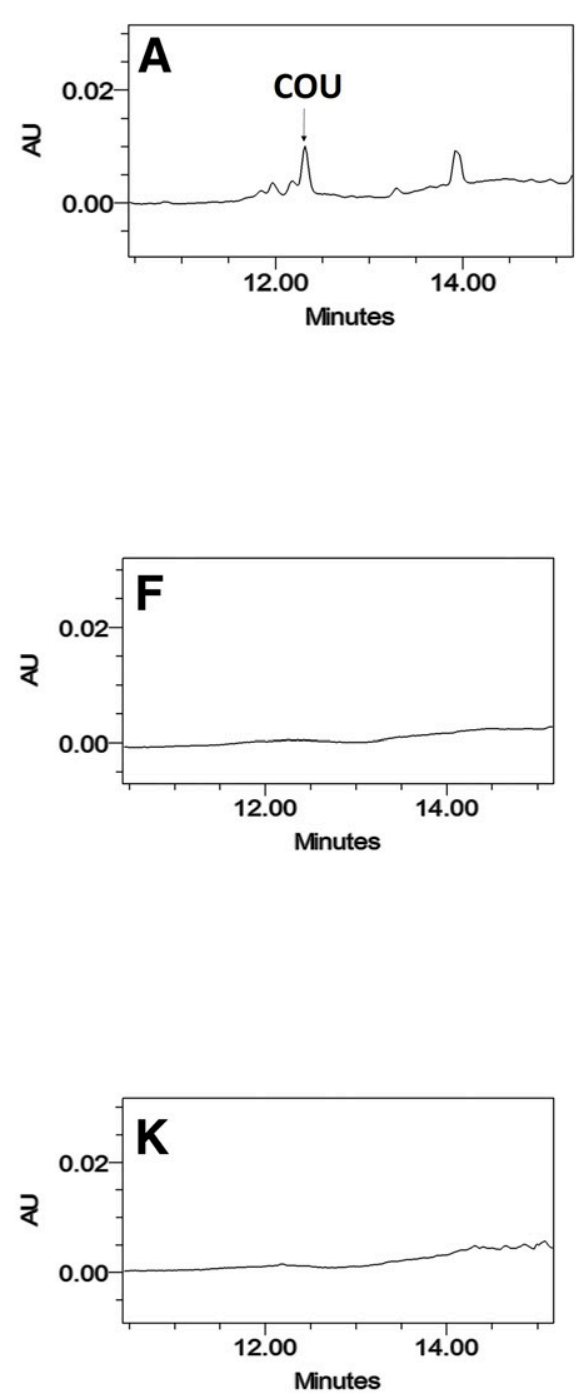

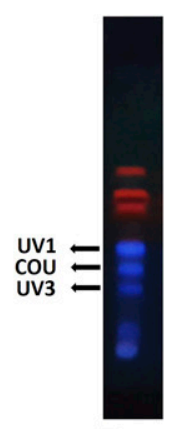

B

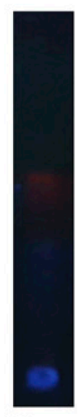

G

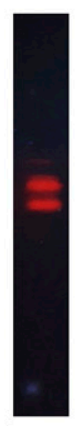

$\mathbf{L}$
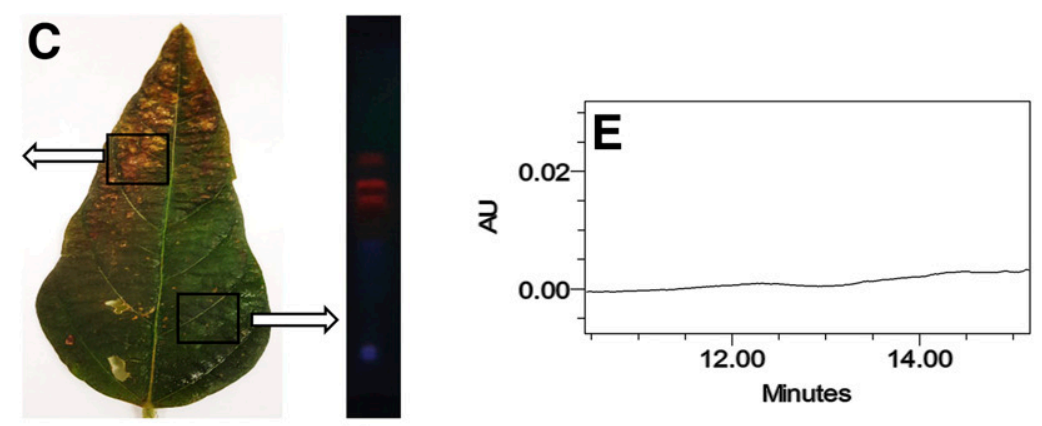

D
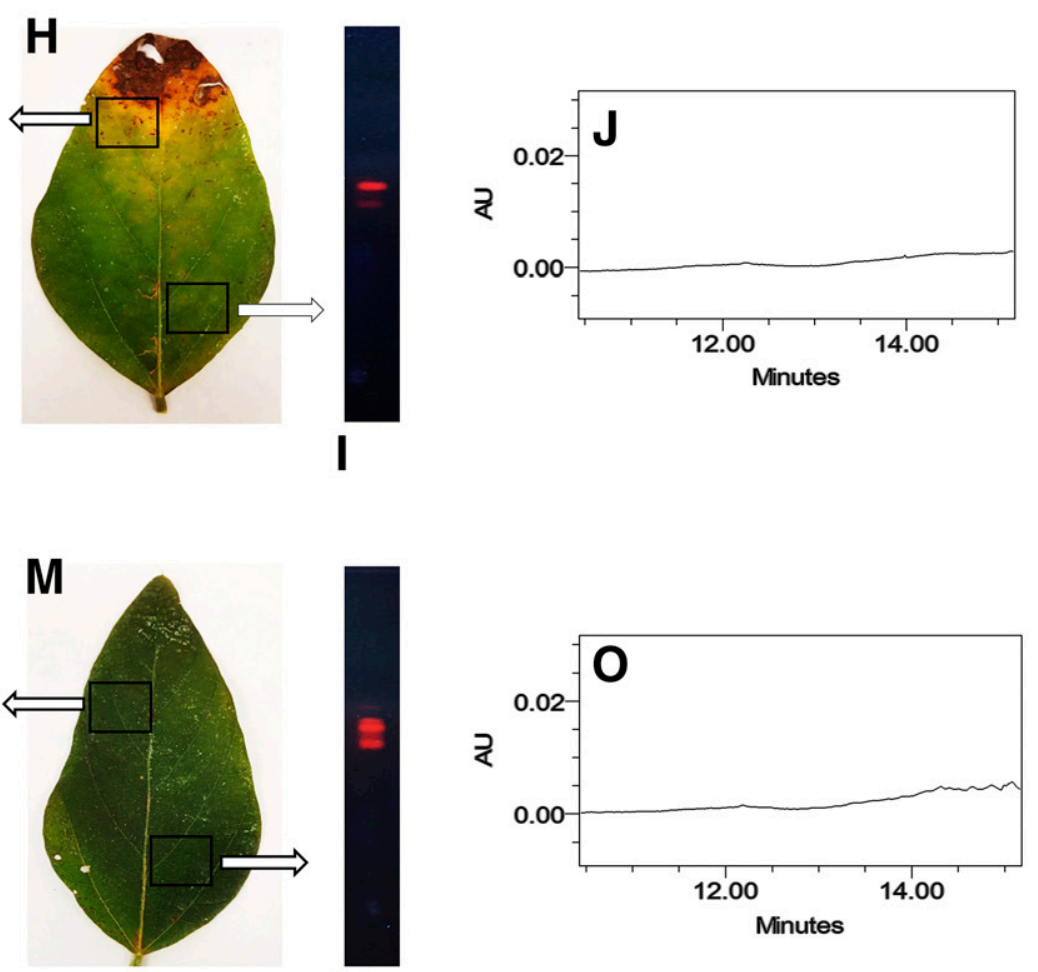

$\mathbf{N}$

Fig. 7. B, D, G, I, L, and N, Thin-layer chromatographic (TLC) and A, E, F, J, K, and $\mathbf{O}$, high-performance liquid chromatographic profiles of symptomatic and asymptomatic areas of $\mathbf{C}$, purple and $\mathbf{H}$, blighted leaves of soybean cultivar Pioneer P49T09 BR affected by Cercospora leaf blight. M, Two areas from an asymptomatic leaf were used as controls. Coumestrol (COU) was detected only in the purple areas from symptomatic leaves (A and C). TLC analysis were performed for qualitative measurements only. 
irradiation (Beggs et al. 1985), and water stress (Tripathi et al. 2016) were associated with accumulation of COU in plant tissue.

Despite its classification as a phytoalexin, COU at 19 and $190 \mu \mathrm{M}$ did not inhibit growth of three isolates of Cercospora cf. flagellaris
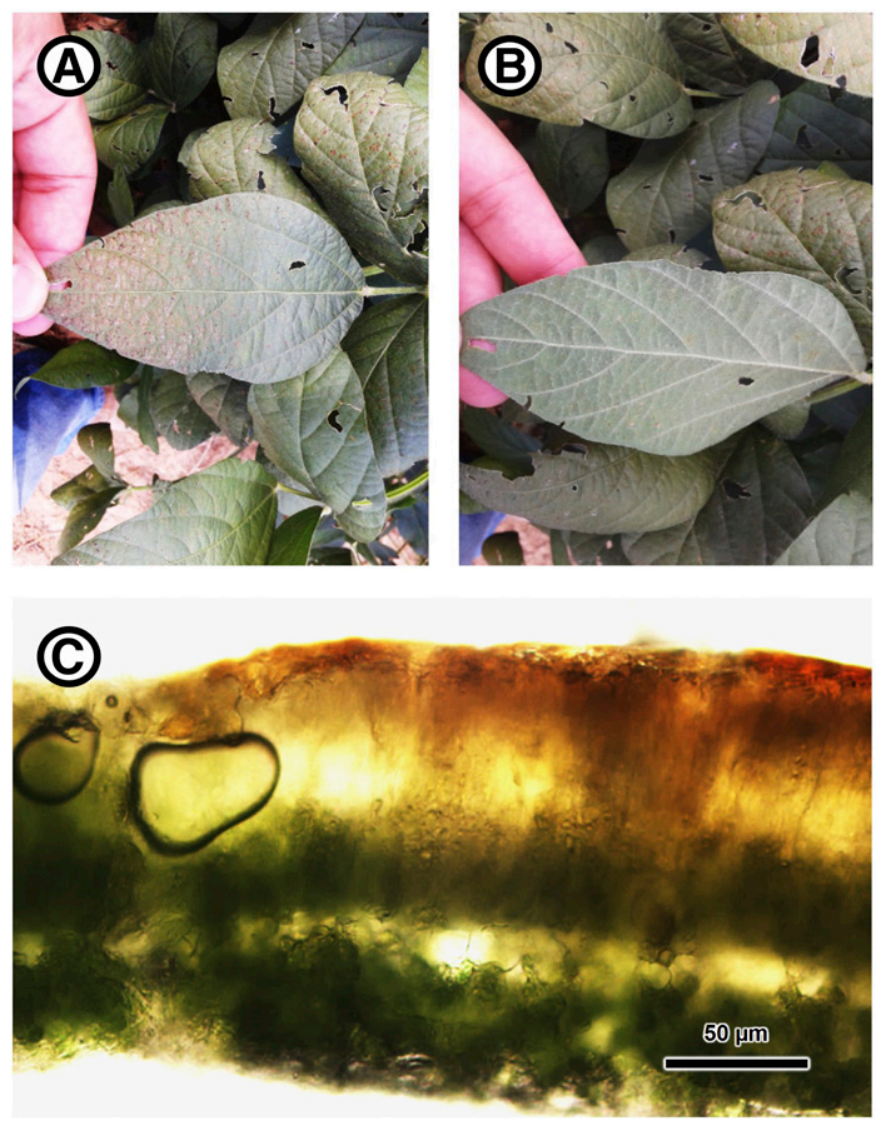

Fig. 8. A, Adaxial side of a soybean leaf showing purple symptoms of Cercospora leaf blight. B, Abaxial side of the same leaf shown in A, in which the purple discoloration of the leaf is not present. C, Freehand section of a soybean leaf observed with a microscope $(\times 40)$ showing brown or purplish coloration only on the adaxial surface of the leaf. in PDA or V8 agars. Previous findings demonstrated the limited but important phytoalexin activity of COU against Fusarium solani $\mathrm{f}$. sp. glycines (Lozovaya et al. 2004), Pseudomonas glycinea (Keen et al. 1974), and $P$. syringae pv. glycinea (Fett and Osman 1982).

However, COU has a strong antioxidant activity, as demonstrated by the DPPH analyses. The high concentration of COU in purple leaves suggests that the pheylpropanoid pathway was triggered to produce classes of flavonoids that have high antioxidant activity but not necessarily high antifungal activity.

Results from the single-leaf experiment showed that COU is predominantly present in the pigmented areas of purple leaves, and its concentration is significantly lower in asymptomatic areas of purple leaves. These results agree with other findings, in which COU was found primarily in lesioned tissues caused by pathogens and insects (Loper et al. 1967; Keen and Taylor 1975; Loper 1968; Seguin et al. 2004; Sherwood et al. 1970). In addition, our visual and microscopic observations showed that the purple discoloration of leaves affected by CLB is localized on the adaxial surfaces of leaves in the upper canopy of soybean plants. Because COU has the highest absorption peak in the UV spectrum (Yuk et al. 2011), it is reasonable to suggest that $\mathrm{COU}$ acts as a sunscreen for the soybean plant. Other compounds, often colorless flavonoids, accumulate in plants undergoing stress mediated by light (Agati and Tattini 2010; Demmig-Adams and Adams 1992; Landry et al. 1995; Long et al. 1994; Mazza et al. 2000; Ryan et al. 2002).

In addition to cercosporin, UV light induces production of ROS that can damage leaf tissue. Although COU might not interfere with cercosporin production and activation, because the absorption spectrum of COU does not overlap with the absorption spectra of cercosporin (Daub et al. 1992), COU may block UV light and scavenge the ROS produced by both cercosporin and UV light. By scavenging ROS that is produced by these two stressors in sunexposed portions of leaves, COU may reduce leaf damage and physiological imbalance, as observed in purple leaves compared with blighted leaves.

Identification of COU as a compound related to purple discoloration triggered by $C$. cf. flagellaris is in line with several studies that found an association between discoloration (red-brown, magenta, or purple) and accumulation of phytoalexins, including COU (Graham and Graham 1996; Ingham et al. 1981; Keen and Taylor 1975; Lozovaya et al. 2004; Zähringer et al. 1980). A
A

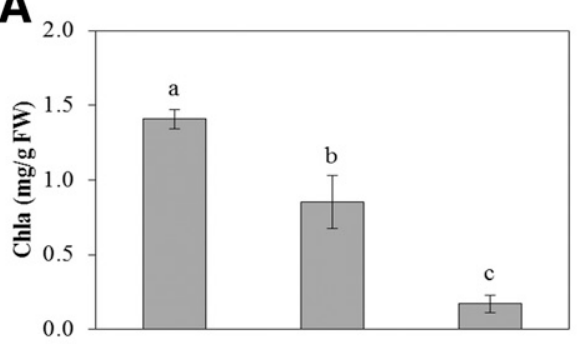

D

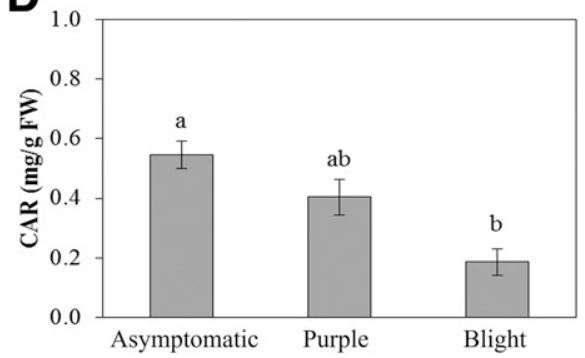

B

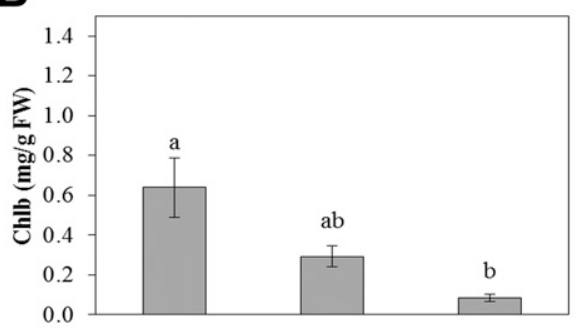

E

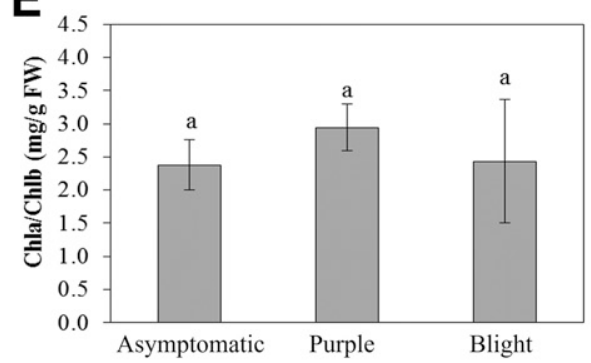

C

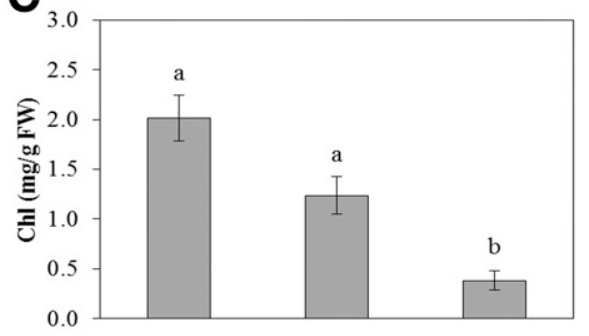

$\mathbf{F}$

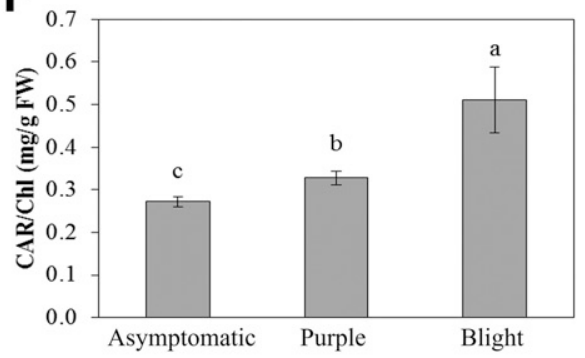

Fig. 9. Concentrations of A, chlorophyll $a(\mathrm{Chl} a) ; \mathbf{B}$, chlorophyll $b(\mathrm{Chl} b)$; C, total chlorophyll (Chl); D, carotenoids (CAR); E, ratio of Chla to Chl $b$ (Chl $a / \mathrm{Chl} b)$; and $\mathbf{F}$, ratio of $\mathrm{Chl}$ to carotenoid (Chl/CAR) on asymptomatic, purple, and blighted leaves of the soybean cultivar Pioneer P49T09 BR affected by Cercospora leaf blight. Means followed by different letters are significantly different by Tukey's post hoc multiple comparison test $(P<0.05)$. Bars represent standard error $(n=3)$. Experiment was repeated once with similar results. 
reddish-brown discoloration and high levels of COU were found in soybean roots after being challenged by $F$. solani (Lozovaya et al. 2004). Wounded soybean cotyledons treated with elicitors from Phytophthora sojae produced red-colored pigmentation associated with COU and glyceollins (Graham and Graham 1996). Red-brown discoloration and phytoalexin accumulation were found in soybean leaves challenged with Pseudomonas syringae pv. pisi (Ingham et al. 1981). Note that discoloration of plant tissue as well as accumulation of phytoalexins are induced by different biotic and abiotic stresses related to ROS production. Thus, we propose that $\mathrm{COU}$ accumulation is a nonspecific plant response leading to ROS scavenging. Another line of evidence was provided by Keen and Taylor (1975), who demonstrated a red-brown hypersensitive resistance reaction and the accumulation of $\mathrm{COU}$ in soybean leaves treated with low doses of ozone; however, high doses led to necrosis of foliar tissue. This seems to mimic CLB, and this suggests that it may be possible to screen for resistance to CLB by screening for resistance to oxidative stress induced by ozone.

Even though COU is associated with red, red-brown, magenta, and purple discoloration of plant tissue affected by ROS-induced stresses, this coumestan is not the direct cause of discoloration. COU is a colorless compound. Independent research groups identified pterocarpan derivatives as the cause of the red-brown or purple discoloration of soybean cotyledons treated with elicitors from Phytophthora sojae (M. Y. Graham and Graham 1991; T. L. Graham and Graham 1991, 1996) and soybean leaves treated with sodium iodoacetate or challenged by Pseudomonas syringae pv. pisi (Ingham et al. 1981). Derivatives of the pterocarpans 3,6a,9-trihydroxypterocarpan (glycinol), 4-dimethylallyl-3,6a,9-trihydroxypterocarpan (glyceollidin I), and 2-dimethylallyl-3,6a,9-trihydroxypterocarpan (glyceollidin II) are closely related to COU and glyceollins, and they are the compounds responsible for the reddish discoloration of plant tissue in the examples cited above.

Cercosporin accumulation, which was thought to be the cause of purple discoloration of soybean leaves affected by CLB, was found in lower concentrations in the purple leaf symptom as compared with blighted leaves (Silva et al. 2015), suggesting that cercosporin is not the direct cause of the purple pigmentation. Neither carotenoids nor anthocyanins were related to the purple leaf symptom of CLB. Knowing the nonspecific response of plants to ROS-inducing stresses, it seems likely that pterocarpan derivatives also are the cause of purple discoloration of soybean leaves infected with $C$. cf. flagellaris. However, additional analyses are required to comprehensively characterize this symptom.

TABLE 4. Scavenging effect (SE) of standard solutions of coumestrol and gallic acid

\begin{tabular}{lccc}
\hline Sample & Concentration $(\mu \mathrm{M})^{\mathrm{y}}$ & Absorbance at $517 \mathrm{~nm}$ & $\mathrm{SE}(\%)^{\mathrm{z}}$ \\
\hline Coumestrol & Negative control & $0.265 \pm 0.001$ & $\mathrm{NA}$ \\
& 2 & $0.264 \pm 0.002$ & $0.6 \pm 0.6 \mathrm{e}$ \\
& 10 & $0.236 \pm 0.003$ & $10.9 \pm 1.1 \mathrm{~d}$ \\
& 20 & $0.233 \pm 0.002$ & $12.2 \pm 0.9 \mathrm{~d}$ \\
Gallic acid & 40 & $0.192 \pm 0.000$ & $27.5 \pm 0.9 \mathrm{c}$ \\
& 60 & $0.188 \pm 0.002$ & $29.1 \pm 0.6 \mathrm{c}$ \\
& 80 & $0.163 \pm 0.001$ & $38.4 \pm 1.1 \mathrm{~b}$ \\
& 100 & $0.125 \pm 0.001$ & $53.0 \pm 0.3 \mathrm{a}$ \\
& 2 & $0.263 \pm 0.002$ & NA \\
& 20 & $0.216 \pm 0.000$ & $18.1 \pm 0.7 \mathrm{f}$ \\
& 40 & $0.095 \pm 0.001$ & $63.9 \pm 1.1 \mathrm{e}$ \\
& 60 & $0.045 \pm 0.001$ & $83.0 \pm 0.8 \mathrm{~d}$ \\
& 80 & $0.025 \pm 0.001$ & $88.6 \pm 0.1 \mathrm{c}$ \\
& 100 & $0.021 \pm 0.000$ & $90.3 \pm 0.9 \mathrm{bc}$ \\
& $20.8 \pm 0.2 \mathrm{~b}$ \\
& $0.014 \pm 0.001$ & $94.5 \pm 0.2 \mathrm{a}$ \\
\hline
\end{tabular}

y Negative control $=1.0 \mathrm{ml}$ of $0.1 \mathrm{mM}$ 2,2-diphenyl-1-picryl-hydrazyl was added to $3 \mathrm{ml}$ of methanol.

$\mathrm{z}$ Means followed by different letters are significantly different according to Tukey's post hoc multiple comparison test $(P<0.01, n=3)$. NA $=$ not applicable.
Several researchers described different biotic and abiotic stress symptoms related to COU accumulation, and they discussed the reddish discoloration of tissue as a "hyposensitive resistance response," "resistance reaction", or "stress response" (Aisyah et al. 2013; Keen and Taylor 1975; Tripathi et al. 2016). Because the purple CLB symptom is associated with lower biomass of $C$. cf. flagellaris and lower cercosporin concentrations as compared with blighted leaves (Silva et al. 2015), we conclude that the purple symptom is a disease resistance reaction that provides a high level of antioxidant activity and, hence, partial resistance.

In summary, results from this work indicate that the purple discoloration of leaves affected by CLB is a response to oxidative stress induced by cercosporin, which is a well-known inducer of ROS. The plant responds to this stress by producing COU, an effective antioxidant and sunscreen. We suspect that the purple discoloration is a stress response in which pterocarpin derivatives are produced, which is a common reaction to biotic and abiotic stresses. If pathogen biomass and cercosporin production exceed the plant's antioxidant capability, then chlorosis and blight symptoms would ensue. Therefore, the purple leaf symptom in soybean plants affected by CLB may be considered to be a partial resistance response to endophytic infection by the pathogen.

\section{ACKNOWLEDGMENTS}

We thank an anonymous reviewer for critical comments and suggestions.

\section{LITERATURE CITED}

Agati, G., and Tattini, M. 2010. Multiple functional roles of flavonoids in photoprotection. New Phytol. 186:786-793.

Aisyah, S., Gruppen, H., Madzora, B., and Vincken, J. P. 2013. Modulation of isoflavonoid composition of Rhizopus oryzae elicited in soybean (Glycine max) seedlings by light and wounding. J. Agric. Food Chem. 61: 8657-8667.

Albu, S., Schneider, R. W., Price, P. P., and Doyle, V. P. 2016. Cercospora cf. flagellaris and Cercospora cf. sigesbeckiae are associated with Cercospora leaf blight and purple seed stain on soybean in North America. Phytopathology 106:1376-1385.

Almeida, A. M. R., Piuga, F. F., Marin, S. R. R., Binneck, E., Sartori, F., Costamilan, L. M., Teixeira, M. R. O., and Lopes, M. 2005. Pathogenicity, molecular characterization, and cercosporin content of Brazilian isolates of Cercospora kikuchii. Fitopatol. Bras. 30:594-602.

Beggs, C. J., Stoltzer-Jehle, A., and Wellman, E. 1985. Isoflavonoid formation as an indicator of UV stress in bean (Phaseolus vulgaris L.) leaves: The significance of photo-repair in assessing potential damage by increased UVB radiation. Plant Physiol. 79:630-634.

Blanco, G., Hornero-Me'ndez, D., Lambertucci, S. A., Bautista, L. M., and Wiemeyer, G. 2013. Need and seek for dietary micronutrients: Endogenous regulation, external signaling and food sources of carotenoids in New World vultures. PLoS One 8:e65562.

Blois, M. S. 1958. Antioxidant determinations by the use of a stable free radical. Nature 181:1199-1200.

Boué, S. M., Carter, C. H., Ehrlich, K. C., and Cleveland, T. E. 2000. Induction of the soybean phytoalexins coumestrol and glyceollin by Aspergillus. J. Agric. Food Chem. 48:2167-2172.

Cai, G., and Schneider, R. W. 2005. Vegetative compatibility groups in Cercospora kikuchii, the causal agent of Cercospora leaf blight and purple seed stain in soybean. Phytopathology 95:257-261.

Cai, G., Schneider, R. W., and Padgett, G. B. 2009. Assessment of lineages of Cercospora kikuchii in Louisiana for aggressiveness and screening soybean cultivars for resistance to Cercospora leaf blight. Plant Dis. 93:868-874.

Chanda, A. K., Ward, N. A., Robertson, C. L., Chen, Z. Y., and Schneider, R. W. 2014. Development of a quantitative polymerase chain reaction detection protocol for Cercospora kikuchii in soybean leaves and its use for documenting latent infection as affected by fungicide applications. Phytopathology 104:1118-1124.

Christie, P. J., Alfenito, M. R., and Walbot, V. 1994. Impact of low temperature stress on general phenylpropanoid and anthocyanin pathways: Enhancement of transcript abundance and anthocyanin pigmentation in maize seedings. Planta 194:541-549.

Daub, M. E., and Briggs, S. P. 1983. Changes in tobacco cell membrane composition and structure caused by the fungal toxin, cercosporin. Plant Physiol. 71:763-766. 
Daub, M. E., and Chung, K.-R. 2007. Cercosporin: A photoactivated toxin in plant disease. Online publication. APSnet Feature.

Daub, M. E., Leisman, G. B., Clark, R. A., and Bowden, E. F. 1992. Reductive detoxification as a mechanism of fungal resistance to singlet-oxygen-generating photosensitizers. Proc. Natl. Acad. Sci. USA 89:9588-9592.

Demmig-Adams, B., and Adams, W. W., III. 1992. Photoprotection and other responses of plants to high light stress. Annu. Rev. Plant Physiol. Plant Mol. Biol. 43:599-626.

Dixon, R. A., Achnine, L., Kota, P., Liu, C. J., Reddy, M. S. S., and Wang, L. J. 2002. The phenylpropanoid pathway and plant defense - a genomics perspective. Mol. Plant Pathol. 3:371-390.

Dixon, R. A., Harrison, M. J., and Paiva, N. L. 1995. The isoflavonoid phytoalexin pathway: From enzymes to genes to transcription factors. Physiol. Plant. 93:385-392.

Dixon, R. A., and Paiva, N. L. 1995. Stress-induced phenylpropanoid metabolism. Plant Cell 7:1085-1097.

Erickson, E., Wakao, S., and Niyogi, K. K. 2015. Light stress and photoprotection in Chlamydomonas reinhardtii. Plant J. 82:449-465.

Fajola, A. O. 1978. Cercosporin, a phytotoxin from Cercospora spp. Physiol. Plant Pathol. 13:157-164.

Fett, W. F., and Osman, S. F. 1982. Inhibition of bacteria by the soybean isoflavonoids glyceollin and coumestrol. Phytopathology 72:755-760.

Geisler, L. G. 2013. Purple seed stain and Cercospora blight. Plant Pathology Fact Sheet. University of Nebraska-Lincoln. Online publication. https:// cropwatch.unl.edu/plantdisease/soybean/purple-seed-stain

Graham, M. Y., and Graham, T. L. 1991. Rapid accumulation of anionic peroxidases and phenolic polymers in soybean cotyledon tissues following treatment with Phytophthora megasperma f. sp. glycinea wall glucan. Plant Physiol. 97:1445-1455.

Graham, T. L., and Graham, M. Y. 1991. Glyceollin elicitors induce major but distinctly different shifts in isoflavonoid metabolism in proximal and dista1 soybean cell populations. Mo1. Plant-Microbe Interact. 4:60-68.

Graham, T. L., and Graham, M. Y. 1996. Signaling in soybean phenylpropanoid responses. Plant Physiol. 110:1123-1133.

Grayer, R. J., and Kokubun, T. 2001. Plant-fungal interactions: The search for phytoalexins and other antifungal compounds from higher plants. Phytochemistry 56:253-263.

Gross, J. 1991. Pigments in Vegetables. Van Nostrand Reinhold, New York.

Hahlbrock, K. 1981. Flavonoids. Pages 425-456 in: Biochemistry of Plants, Vol. 7. P. K. Stumpf, and E. E. Conn, eds. Academic Press, New York.

Harborne, J. B. 1999. The comparative biochemistry of phytoalexin induction in plants. Biochem. Syst. Ecol. 27:335-367.

Hershman, D. 2009. Cercospora leaf blight in Kentucky. Plant Pathology Fact Sheet PPFS-AG-S-20. Online publication. University of Kentucky Cooperative Extension Service. http://plantpathology.ca.uky.edu/files/ppfs-ag-s-20.pdf

Ilyas, M. B., Dhingra, O. D., Ellis, M. A., and Sinclair, J. B. 1975. Location of mycelium of Diaporthe phaseolorum var. sojae and Cercospora kikuchii in infected soybean seeds. Plant Dis. 59:17-19.

Ingham, J. L., Keen, N. T., Mulheirn, L. J., and Lyne, R. L. 1981. Induciblyformed isoflavonoids from leaves of soybean. Phytochemistry 20:795-798.

Jeon, H. Y., Seo, D. B., Shin, H.-J. and Lee, S.-J. 2012. Effect of Aspergillus oryzae-challenged germination on soybean isoflavone content and antioxidant activity. J. Agric. Food Chem. 60:2807-2814.

Keen, N. T., and Kenn-Edy, B. W. 1974. Hydroxyphaseollin and related isoflavonoids in the hypersensitive resistance reaction of soybeans to Pseudomonas glycinea. Physiol. Plant Pathol. 4:173-185.

Keen, N. T., and Taylor, C. 1975. Ozone injury in soybeans, isoflavonoid accumulation is related to necrosis. Plant Physiol. 55:731-733.

Kilpatrick, R. A., and Johnson, H. W. 1956. Sporulation of Cercospora species on carrot leaf decoction agar. Phytopathology 46:180-181.

Landry, L. G., Chapple, C. C., and Last, R. L. 1995. Arabidopsis mutants lacking phenolic sunscreens exhibit enhanced ultraviolet-B injury and oxidative damage. Plant Physiol. 109:1159-1166.

Levy, R., Padgett, B., Lofton, J., Harrell, D., Stevens, J., Stephenson, D., Viator, S., Udeigwe, T. K., Hollier, C., Haggard, B. J., Buckley, B., Davis, J., and Bollich, P. 2013. Soybean Variety Yields and Production Practices. Online publication. http://www.lsuagcenter.com/NR/rdonlyres/A3A3A6A70AFC-4106-9B27-2D2E55F93CDA/89921/pub2269Soybeans Variety2013. pdf

Li, J., Ou-Lee, T.-M., Raba, R., Amundson, R. G., and Last, R. L. 1993. Arabidopsis flavonoid mutants are hypersensitive to UV-B irradiation. Plant Cell 5:171-179.

Lichtenthaler, H. K. 1987. Chlorophylls and carotenoids, the pigments of photosynthetic biomembranes. Pages 350-382 in: Methods in Enzymology. R. Douce and L. Packer, eds. Academic Press Inc., New York.

Lois, R. 1994. Accumulation of UV-absorbing flavonoids induced by UV-B radiation in Arabidopsis thaliana L. Planta 194:498-503.

Long, S. P., Humphries, S., and Falkowski, P. G. 1994. Photoinhibition of photosynthesis in nature. Annu. Rev. Plant Physiol. Plant Mol. Biol. 45:633-662.
Loper, G. M. 1968. Effect of aphid infestation on the coumestrol content of alfalfa varieties differing in aphid resistance. Crop Sci. 8:104-106.

Loper, G. M., Hanson, C. H., and Graham, J. H. 1967. Coumestrol content of alfalfa as affected by selection for resistance to foliar diseases. Crop Sci. 7: 189-192.

Lozovaya, V. V., Lygin, A. V., Zernova, O. V., Li, S., Hartman, G. L., and Widholm, J. M. 2004. Isoflavonoid accumulation in soybean hairy roots upon treatment with Fusarium solani. Plant Physiol. Biochem. 42:671-679.

Lygin, A. V., Li, S., Vittal, R., Widholm, J. M., Hartman, G. L., and Lozovaya, V. V. 2009. The importance of phenolic metabolism to limit the growth of Phakopsora pachyrhizi. Phytopathology 99:1412-1420.

Lygin, A. V., Zernova, O. Z., Hill, C. B., Kholina, N. A., Widholm, J. M., Hartman, G. L., and Lozovaya, V. V. 2013. Glyceollin is an important component of soybean plant defense against Phytophthora sojae and Macrophomina phaseolina. Phytopathology 103:984-994.

Lyngkjær, M. F., and Carver, T. L. W. 1999. Induced accessibility and inaccessibility to Blumeria graminis f. sp. hordei in barley epidermal cells attached by a compatible isolate. Physiol. Mol. Plant Pathol. 55:151-162.

Mazza, C. A., Boccalandro, H. E., Giordano, C. V., Battista, D., Scopel, A. L., and Ballaré, C. L. 2000. Functional significance and induction by solar radiation of ultraviolet absorbing sunscreens in field-grown soybean crops. Plant Physiol. 122:117-126.

Moore, S. H., and Wolcott, M. C. 2000. Using yield maps to create management zones in field crops. Louis. Agric. 43:12-13.

Mostrom, M., and Evans, T. J. 2011. Phytoestrogens. Pages 707-722 in: Reproductive and Developmental Toxicology. R. C. Gupta, ed. Elsevier Inc.

Patel, R. M., and Patel, N. J. 2011. In vitro antioxidant activity of coumarin compounds by DPPH: Superoxide and nitric oxide free radical scavenging methods. J. Adv. Pharm. Technol. Res. 1:52-68.

Paxton, J. D. 1981. Phytoalexins-A working redefinition. Phytopathol. Z. 101:106-109.

Porra, R. J., Thompson, W. A., and Kriedemann, P. E. 1989. Determination of accurate extinction coefficients and simultaneous equations for assaying chlorophylls a and $\mathrm{b}$ extracted with four different solvents: Verification of the concentration of chlorophyll standards by atomic absorption spectroscopy.. Biochim. Biophys. Acta 975:384-394.

Price, P., Padgett, G. B., and Purvis, M. A. 2013. The effect of selected fungicides, application rates, and application timings to soybean. Plant Dis. Manage. Rep. 7:FC055

Price, P. P., Purvis, M. A., Cai, G., Padgett, G. B., Robertson, C. L., Schneider, R. W., and Albu, S. 2015. Fungicide resistance in Cercospora kikuchii, a soybean pathogen. Plant Dis. 99:1596-1603.

Rich, J. R., Keen, N. T., and Thomason, I. J. 1977. Association of coumestans with tee hypersensitivity of lima bean roots to Pratylenchus scriberni. Physiol. Plant Pathol. 10:105-116.

Rodriguez-Amaya, D. B. 2001. Some physicochemical properties of carotenoids. Pages 14-23 in: A Guide to Carotenoid Analysis in Foods. OMNI Research ILSI Human Nutrition Institute, ILSI Press, Washington, DC.

Ryan, K. G., Swinny, E. E., Markham, K. R., and Winefield, C. 2002. Flavonoid gene expression and UV photoprotection in transgenic and mutant Petunia leaves. Phytochemistry 59:23-32.

Scarpari, L. M., Meinhardt, L. W., Mazzafera, P., Pomella, A. W., Schiavinato, M. A., Cascardo, J. C., and Pereira, G. A. 2005. Biochemical changes during the development of witches' broom: The most important disease of cocoa in Brazil caused by Crinipellis perniciosa. J. Exp. Bot. 56:865-877.

Schneider, R. W., Bollich, P. K., and Harville, B. G. 2003. Evaluation of soybean cultivars for reactions to three foliar diseases. B\&C Tests Online 18:P003.

Seguin, P., Zheng, W., and Souleimanov, A. 2004. Alfalfa phytoestrogen content: Impact of plant maturity and herbage components. J. Agron. Crop Sci. 190:211-217.

Sherwood, R. T., Olah, A. F., Oleson, W. H., and Jones, E. E. 1970. Effect of disease and injury on accumulation of flavonoid the estrogen, coumestrol, in alfalfa. Phytopathology 60:684-688

Silva, E. C., Garcia, T. G., Lygin, A. V., Chanda, A. K., Robertson, C. L., Ward, B. M., and Schneider, R. W. 2015. A new perspective on Cercospora leaf blight symptoms on soybean. In: Proc. South. Soybean Dis. Workers 40th Annu. Meet. Pensacola Beach, FL.

Siupp, R. A., and Bailey, J. A. 1977. The fungitoxicity of isoflavonoid phytoalexins measured using different types of bioassays. Physiol. Plant Pathol. 11:101-112.

Soares, A. P. G., Guillin, E. A., Borges, L. L., Leandro, L. B., da Silva, A. C. T., de Almeida, A. M. R., Grijalba, P. E., Bluhm, B. H., and de Oliveira, L. O. 2015. More Cercospora species infect soybean across the Americas than meets the eye. PLoS One 10:e0133495.

Subramanian, S., Graham, M. Y., Yu, O., and Graham, T. L. 2005. RNA interference of soybean isoflavone synthase genes leads to silencing in tissues distal to the transformation site and to enhanced susceptibility to Phytophthora sojae. Plant Physiol. 137:1345-1353. 
Tripathi, P., Rabara, R. C., Reese, R. N., Miller, M. A., Rohila, J. S., Subramanian, S., Shen, Q. J., Morandi, D., Bücking, H., Shulaev, V., and Rushton, P. J. 2016. A toolbox of genes, proteins, metabolites and promoters for improving drought tolerance in soybean includes the metabolite coumestrol and stomatal development genes. BMC Genomics 17:102.

Upchurch, R. G., Walker, D. C., Rollins, J. A., Ehrenshaft, M., and Daub, M. E. 1991. Mutants of Cercospora kikuchii altered in cercosporin synthesis and pathogenicity. Appl. Environ. Microbiol. 57:2940-2945.

Velicheti, R. K., and Sinclair, J. B. 1994. Production of cercosporin and colonization of soybean seed coats by Cercospora kikuchii. Plant Dis. 78: 342-346.

Walters, H. J. 1980. Soybean leaf blight caused by Cercospora kikuchii. Plant Dis. 64:961-962.

Weiss, F. A. 1957. Maintenance and preservation of cultures. Pages 99-119 in: Manual of Microbiological Methods. H. J. Conn, ed. Society of American Bacteriologists. McGraw-Hill Book Company, Inc., New York.

Wrather, A., Shannon, G., Balardin, R., Carregal, L., Escobar, R., Gupta, G. K., Ma, Z., Morel, W., Ploper, D., and Tenuta, A. 2010. Effect of diseases on soybean yield in the top eight producing countries in 2006. Online publication. Plant Health Prog. doi:10.1094/PHP-2010-0125-01-RS

Wrather, J. A., Anderson, T. R., Arsyad, D. M., Gai, J., Ploper, L. D., Porta-Puglia, A., Ram, H. A., and Yorinori, J. T. 1997. Soybean disease loss estimates for the top 10 soybean producing countries in 1994. Plant Dis. 81:107-110.

Young, A. J. 1991. The photoprotective role of carotenoids in higher plants. Physiol. Plant. 83:702-708.

Yuk, H. J., Curtis-Long, M. J., Ryu, H. W., Jang, K. C., Seo, W. D., Kim, J. Y., Kang, K. Y., and Park, K. H. 2011. Pterocarpan profiles for soybean leaves at different growth stages and investigation of their glycosidase. J. Agric. Food Chem. 59:12683-12690.

Zähringer, U., Schaller, E., and Grisebach, H. 1980. Induction of phytoalexin synthesis in soybean. Structure and reactions of naturally occurring and enzymatically prepared prenylated pterocarpans from elicitor-treated cotyledons and cell cultures of soybean. Z. Naturforsch. C J. Biosci. 36:234-241.

Zhao, Y.-R., Li, X., Yu, K.-Q., Cheng, F., and He, Y. 2016. Hyperspectral imaging for determining pigment contents in cucumber leaves in response to angular leaf spot disease. Sci. Rep. 6:Article 27790. 